\title{
Development and Validation of a New Variable Refrigerant FlowSystem Model in EnergyPlus
}

Tianzhen Hong ${ }^{1 *}$, Kaiyu Sun ${ }^{1}$, Rongpeng Zhang ${ }^{1}$, Ryohei Hinokuma ${ }^{2}$, Shinichi Kasahara ${ }^{3}$, Yoshinori Yura ${ }^{3}$

${ }^{1}$ Building Technology and Urban Systems Division

Lawrence Berkeley National Laboratory

1 Cyclotron Road, Berkeley, CA 94720, USA

${ }^{2}$ Daikin US Corporation

475 Fifth Avenue, 18th floor

New York, NY 10017, USA

${ }^{3}$ Daikin Industries LTD

UmedaCenter Bldg., 2-4-12,

Nakazaki-Nishi, Kita-ku, Osaka, 530-8323, Japan

" Corresponding author. Tel: +1-510-4867082; Fax: +1-510-4864089

E-mail address: thong@1bl.gov 


\title{
Development and Validation of a New Variable Refrigerant FlowSystem Model in EnergyPlus
}

\begin{abstract}
Variable Refrigerant Flow (VRF) systems vary the refrigerant flow to meet the dynamic zone thermal loads, leading to more efficient operations than other system types. This paper introduces a new model that simulates the energy performance of VRF systems in the heat pump (HP) operation mode. Compared with the current VRF-HP models implemented in EnergyPlus, the newVRF system modelhas more component models based on physics and thushas significant innovations in: (1) enabling advanced controls, including variable evaporating and condensing temperatures in the indoor and outdoor units, and variable fan speeds based on the temperature and zone load in the indoor units, (2) adding a detailed refrigerant pipe heat loss calculation using refrigerant flow rate, operational conditions, pipe length, and pipe insulation materials, (3) improving accuracy of simulation especially in partial load conditions, and (4) improving the usability of the model by significantly reducing the number of user input performance curves. The VRF-HPmodel is implemented in EnergyPlus and validated with measured data from field tests. Results show that the newVRF-HP model providesmore accurate estimate of the VRF-HP system performance, which is key to determining code compliance credits as well as utilities incentive for VRF technologies.
\end{abstract}

Keywords: Variable Refrigerant Flow; heat pump, EnergyPlus, building simulation, energy modeling, model validation 


\section{Introduction}

The building sector consumes more than $30 \%$ of the total energy worldwide [1]. The energy consumed by both residential and commercial buildings has steadily increased reaching figures between $20 \%$ and $40 \%$ in developed countries, exceeding the industrial and transportation sectors[2]. The significant increase in building energy use is mainly due to the spread of HVAC installations in response to the growing demand for better thermal comfort within the built environment[3]. In developed countries, HVAC accounts for almost half of the total energy consumption incommercial buildings. Therefore, it is crucial to improve the energy efficiency of HVAC systems to save on building energy and reduce carbon emissions[4-7].

Variable Refrigerant Flow (VRF) system is a refrigerant system that varies the refrigerant flow rate usingvariable speed compressor(s) in the outdoor unit, and the electronic expansion valves (EEVs) located in each indoor unit. The systemmeets the space cooling or heating load requirements bymaintaining the zone air temperature at the setpoint[8].Itsability tocontrol the refrigerant mass flow rate according to the cooling and/or heating load enables the use of as many as 60 or more indoor units with differing capacities in conjunction with one single outdoor unit.Thisunlocks the possibility ofhaving individualized comfort control, simultaneous heatingand cooling in different zones, and heat recovery from one zone toanother $[8,9]$.There are two common ways to arrange VRF systems with two-pipe orthree-pipe configurations. The twopipe VRF system, known as the VRF Heat Pump system, is the most general type that can be used for cooling or heating, but not simultaneously. The three-pipe (a high pressure gas pipe, a low pressure gas pipe, and a low pressure liquid pipe) VRF system, known as the VRF Heat Recovery system,can deliver simultaneous heating and cooling to different zones by transferring heat between the cooling and heating indoor units.Simultaneous heating and coolinggenerally 
occurs in the winter season in medium-sized to large-sized commercial buildings with a substantial core such as computer rooms [10].

VRF systemscan provideflexible controls, betterthermal comfort capabilities, andless energy consumption.This is because of multiple advantages of the VRF system including: (1)more efficient operation during partload conditionswith the help of variable speed compressor and fans; (2) minimal or none ductwork reducesair leakage and heat losses; and (3) smaller indoor unit fans that can consumeless energy while reducing indoor noise[8, 11,12, 13]. A typical VRF system has one outdoor unit serving multiple indoor units. Each indoor unit can have its own thermostat to control its operation, meaning it can be turned off if the zone is not occupied or the indoor air temperaturesetpointis met. Because of the extraordinary performance inindividual and flexible control, VRF systems are perfectly applicable to situations requiring individualized comfort conditioning. As a result, VRF systems are becoming more widely used with sales booming worldwide [14]. Hospitals and nursing homes are good candidates for the VRF system, in order to avoid zone-to-zone air mixing. Residential buildings, especially luxury single-family homes, condos and multi-family residential buildings, tend to use the VRF systems $[9,10]$. VRF systems can also be installed inbuildingswhere strict noise regulations apply, e.g. school buildings[15].

As one of the latest emerging HVAC technologies, VRF systems have beencomprehensively compared with conventional air conditioning systems, such as variable air volume systems, fan coil systems,andpackage ducted systems. It is found thatthe VRF system can consume less energy than the conventional air conditioning systems: $20 \%$ to $58 \%$ less than variable air volume systemsin the cooling season [16-20]; $10 \%$ less than fan-coil plus dedicated outdoor air systems in the cooling season [16]; 35\% less than central chiller/boiler systems under the humid 
subtropical climate conditions[10]; 30\% less than chiller systems under the tropical climate conditions [21].It should be noted that actual savings from VRF systems would vary depending on several factors including climate, operation conditions, and control strategies.The flexibility of zoning and control collectively contribute to extra potential energy savings for buildings, especially those with diversified zonal loads (such as residences) [22, 23, 24].From the perspective of thermal comfort, the individual control allowed by the VRF system enables the adjustment of thermostat settings according to the specific requirements of different users, hence improves the thermal satisfaction $[25,26]$. This was proved by a field-performance test of two different control modes (individual and master) that were applied to the VRF system of the test building [25].Therefore, the VRF system not only consumes less energy than the common air conditioning systems, but also provides better indoor thermal comfort due to its independent zoning controls.As for cost, the high initial cost is one of the main drawbacks of VRF systems, but thesignificant energy saving potential promotes the possibility of payback [10, 21], in addition topotentially improved productivity from better occupant comfort.

VRF models have been developed and implemented in a number of building energy modeling programs, including EnergyPlus (Version 7.2 and later) $[27,28]$, QQUEST (a customized version only, which is not open to public), DOE-2.1Ewith user functions [29], Trace and IES-VE. In these models, a large number of system-level curves are used to describe the operational performance of the overall system. These models can generate satisfactory results for common VRF systemsundernormal conditions, butare usually limitedwhen it comes to the evaluation of advanced VRF systems within which more complex control logics are usually needed to manipulate numerous operational parameters at various conditions. Furthermore, current system-level curvesused to describe VRF-HP systems arebased on outdoor and indoor air 
temperatures, similar to those used by packaged DX systems. However, a VRF-HP systemis quite different, usually with one outdoor unit serving multiple indoor units with individual zonelevel controls considering their potentially different thermostat settings and loads. Therefore the VRF system performance can be better modeled using component level curves for indoor units, outdoor units, and their connecting piping network. This may further limit the evaluation of VRF systemsbeing integrated with other energy saving techniques or implemented with demand response strategies. Sharma et al. [28] compared the lab measured and simulated energy use of VRF systems, using the existing VRF model in EnergyPlus Version 7.2.They observed significant discrepancies in daily and monthly energy consumption, especially at low part-load operating conditions.

To overcome the limitations of existing empirical VRF models andimprove the simulation accuracy, a new VRF system modelwith more physics-based component modelswasdeveloped in this study. It implements component-level performance curves instead of overall system curves. The model wasthen implemented in the EnergyPlus building simulation engine to conduct the annual building energy simulation under realistic weather conditions. Experimental measurementsin a typical California house were conducted for model testing and validation. The lessons learned from the model development, calibration, and validation are discussed.

\section{Model Development and Implementation}

\subsection{Main features of the new model}

The new model aims to simulate the energy performance of VRF systems in the heat pump (HP) operation mode, i.e., either cooling or heating but not simultaneously. Compared with the empirical VRF-HP model currently implemented in several building simulation programs, the 
proposed model strictly adheres toa more physics-based development providing the ability to consider the dynamics of more operational parameters. This is essential for the description of more enhanced VRF control logics, including allowing: (1) variable evaporating and condensing temperatures in the indoor and outdoor units, (2) variable fan speed based on the temperature and zone load in the indoor unit, and (3) further modifications of operational parameters (e.g., evaporating temperature, superheating degrees, and supply air flow rate) during low load conditions. The new VRF-HP model also provides a reliable approach to simulating the VRF system integrated with other energy saving technologies, e.g., dedicated outdoor air system. Furthermore, it enables the potential simulation of demand response of VRF systems by directly slowing down the speed of compressors in the outdoor units with invertertechnology.

Another feature of the new model includes the implementation of separate curves for capacities and power inputs of indoor units and outdoor units, instead of overall curves for the entire system.Take compressor for instance, the new model implements a group of curves (Eq. 22 in Appendix A) to describe the compressor energy consumption performance at various speed levels. This feature allows the user to provide fewer performance curves as the model inputs. Specifically, the proposed new model requires only seven types of curves to describe the performance of key components, while the current VRF models often require more than 20 curves to represent the system operation [30]. The definition of VRF performance data for simulation,being developed as part of ASHRAE Standard 205, will ensure VRF manufacturers provide adequate data to create the required performance curves.

Finally, the new VRF model includes an enhanced physics-based model to calculate thermal loss in the main refrigerant piping network,with advantage over using a constant correction factor. The piping loss algorithm takes into account the influence of a number of dynamic factors 
(refrigerant flow rate, operational conditions, and refrigerant properties) and static factors (pipe length, pipe and insulation materials). These features significantly improve the accuracy of the simulated VRF system performance in both heating and cooling modes, especially during low part load operations.

\subsection{Model implementation in EnergyPlus}

The new VRF-HP model is implemented in the EnergyPlus 2015 (fall release).EnergyPlus is an open source program that models heating, ventilation, cooling, lighting, water use, renewable energy generation and other building energy flows [31] and is the flagship building simulation engine supported by the United States Department of Energy.It includes many innovative simulation capabilities including sub-hourly time-steps, modular systems and plant integrated with heat balance-based zone simulation, multi-zone air flow, thermal comfort, water use, natural ventilation, renewable energy systems, and user customizable energy management system. Each release of EnergyPlus is continually tested extensively using more than four hundred example files and the test cases are defined in the ASHRAE Standard 140 [32]. It is a powerful tool that supportsbuilding professionals, scientists and engineers inoptimizingbuilding design and operations, and thus helps to reduceenergy and water consumption.

The current VRF models stay in EnergyPlus for backward compatibility purpose. Comparisons between the current and the new VRF models were performed and are discussed later in the article.

\subsection{Summary of the calculation procedures}

The VRF system can be divided into a number of sub-systems, each of which is described by a specificIDD (Input Data Dictionary)object in EnergyPlus. Figure 1 shows how these objects are connected to each other to form the whole VRF system model. The object 
AirConditioner:VariableRefrigerantFlow:FluidTemperatureControl is used to represent the outdoor unit of a VRF. It connects to a zone terminal unit list, containing multiple ZoneHVAC:TerminalUnit:VariableRefrigerantFlow objects, which describe the configurations of the VRF indoor units. Each zone terminal unit object further refers to several component objects, including the fan, air mixer, and heating and cooling coils. Zone terminal units operate to meet the zone sensible cooling or heating requirements as specified by the zone thermostat settings. At each simulation time step, EnergyPlus performs a zone air heat balance to determine the zonal load, and then the VRF model is executed to simulate the VRF operations to meet the load requirements.

Figure 1: VRF system objects and their connections in EnergyPlus(adapted from [30])

In the new VRF model, the effective evaporating temperature (cooling mode) or condensing temperature (heating mode) for the indoor units is first determined based on the load requirements and indoor unit configurations. Then the pressure and heat losses through the main pipe are calculated at the given operational condition. After that, the effective condensing temperature (cooling mode) or evaporating temperature (heating mode) of the outdoor unit is calculated, taking into account the piping loss. With the above calculations, the compressor speed can be chosen using the performance curves describing the evaporative capacity of the system at various condensing/evaporating temperature combinations at various compressor speeds. Finally, the compressor power at that speed is calculated and the total electric power consumption by the outdoor unit is obtained. Detailed descriptions on the algorithm can be found in AppendixA.

One key feature of the proposed model is the capability to adjust operational parameters. This enables the modeling of a multi-stage control strategy to adjust the system capacity during 
low load conditions, as shown in Figure 2. Take the cooling mode for example, the system would first vary the compressor speed to create proper cooling capacity. If the cooling load is even smaller than the cooling capacity corresponding to the minimum speed, the system would increase the evaporating temperature for lower capacity. If the capacity still needs further reduction, the indoor unit air flow rate and the super heating value would be adjusted and the cycling operation may be activated. All of these control strategies require the manipulation of operational parameters, which cannot be achieved in the existing VRF model based on system curves.

Figure 2: Multi-stage control strategy to adjust the system capacity during low load conditions

Also note that a number of calculation steps are coupled together in the new VRF model, for instance, the piping loss calculation and the system performance calculation. More specifically, the piping loss changes the operating conditions of the compressor, which may lead to a different compressor speed and thus affect the amount of piping loss. This makes it difficult to obtain an analytical solution for a number of operational parameters (e.g., enthalpy of refrigerant entering the indoor unit), and therefore numerical iterations are employed to address this problem.

\section{Model Validation with Field Measurement}

\subsection{Field measurement}

To validate VRF algorithms and test the real performance of VRF systems, a VRF system was installed, commissioned and tested in an instrumented house,called theCaleb house, located in Stockton, California. The Caleb house is a two-story single family home with a total conditioned floor area of $205 \mathrm{~m}^{2}\left(88 \mathrm{~m}^{2}\right.$ on the first floor and $117 \mathrm{~m}^{2}$ on the second floor $)$. It was built in 2005, with four bedrooms, a living room, a dining room, a kitchen, a laundry room and three bathrooms. Figure 3 shows the façade of the Caleb house and the VRF system schematic 
based on the floor plans. There are one outdoor unit and four indoor units serving the four zones in the VRF system installed in the Caleb House. The two zones on the first floor are the living room and dining room. One zone on the second floor is the master bedroom, and the other is for the threeother bedrooms. Table 1 summarizes the thermal properties of the Caleb houseenvelope.

\section{Figure 3: The facades of the Caleb house}

\section{Table 1: Thermal properties of the envelope}

For the VRF system, the outdoor unit is located on the ground outside the house. There are four indoor units, two on each floor. On the first floor, one indoor unit is installed in the living room while the other is installed in the kitchen. On the second floor, one indoor unit is installed in the master bedroom, while the other is installed in the hallway to condition the other three bedrooms through the air duct. All the performance data of the VRF system, including supply and return air temperature, energy use of each component, fan speed etc., is monitored by a RAM Monitor, a monitoring tool developed by the VRF manufacturer. The operation of the VRF system is controlled by Manufacturer's Intelligent Control System.

During the field test, the Caleb house wasunoccupied to avoid uncontrollable impacts from occupants. However, to test the real performance of the VRF system, it becamenecessary to create an artificial environment representinga real indoor environment with occupants. For this purpose, additional equipment wasdeployed in the house, including electric heaters, humidifiers and fans. Electric heaters and humidifiers act as occupancy simulators, which are used to create sensible internal loads (mainly from lighting, electric equipment and occupants in a real house) and latent internal loads (mainly from occupants and cooking), respectively. Fans are used to make sure the air is well mixed.The house was operated under controlled conditions simulating 
the normal internal gains as defined in California's Building Energy Efficiency Standards (Title 24) for residential buildings [33].

The house was instrumented with a variety of sensors and meters, including temperature sensors, humidity sensors, and smart meters (Table 2). They wereused to monitor the temperature and humidity of each room and of supply and return air, the on/off status of the electric equipment, and the energy use of all the installed electric equipment. The test house had been running for other experiments ahead of this VRF test. The sensors and meters are of good quality and had been calibrated and were maintained periodically. For example, the temperature sensors measuring the supply and return air temperature of the VRF system have the accuracy of $\pm 0.3^{\circ} \mathrm{C}$; the energy meters measuring the energy use of VRF indoor and outdoor units have the accuracy of $0.5 \%$; the wind speed meter measuring the ambient wind speed has the accuracy of $0.5 \mathrm{~m} / \mathrm{s}$. In this case, the error from measurement would be small thus could be ignored.The thermostat settings werebased on Title 24 standards, producing load patterns similar to those of an actual residence. A weather station wasinstalled outside the Caleb house, monitoring the ambient conditions, including dry-bulb air temperature, humidity, wind speed and solar radiation. All the measured data wascollected perminute, including the energy usage of outdoor unit and indoor fans, onsite weather data, inlet andoutlet temperature/humidity and air flow rate of indoor units. Internal cooling/heating loads were calculated from the measured inlet and outlet temperature/humidity and air flow rate of indoor units, which were then used as the input for the VRF system energy simulation. Onsite weather data was also used in the simulation, which wascritical to avoid bias caused by standardized weather data. Figure 4(a-h) shows the main equipment (i.e. sensors, meters and equipment to generate internal loads) installed in the Caleb house. 
Table 2: List of the Monitored Data Points

Figure 4(a-h): Building systems and sensors including: (a) humidifier, (b) electric heater and fan, (c) temperature and humidity sensor in a guest bedroom, (d) VRF Outdoor unit, (e) Intelligent Control System, (f) smart meter for the whole house, (g) electricity monitoring for the electric heater and fan, and (h) the weather station.

The installation and commissioning of the VRF system in the Caleb house was done in May 2013. The VRF system has continued to runsince inception and detailed measured data has been collected. It should be noted that the Caleb house also has installed three independent HVAC systems: the VRF system, the as-built Title 24-2005 baseline system, and the high efficiency system. The as-built Title 24-2005 baseline system is based on the minimum requirements of California Building Energy Efficiency Standards Title 24-2005. The high efficiency system isthe same type as the baseline HVAC system, but with higher efficiency cooling and heating equipment. Each system runs for two days, then rotates to another system. The measured performance data is then used as the reference for the improvement and validation of the algorithms.

\subsection{Model validation procedure}

To validate the new VRF model, a beta version of EnergyPlus implemented with the proposed VRF model wasused to simulate the energy consumption of the VRF system installed in the Caleb house. The key inputs tothe VRF simulation were: (1) weather data, (2) cooling/heating loads of each conditioned zone, and (3) manufacturer's product specification. To improve the simulation accuracy, it is crucial to input the information as realistic as possible:(1) real-time weather data was measured and collected from onsite weather station; (2) sensible and 
latent cooling/heating loads of each conditioned zone werecalculated from measured inlet and outlet temperature/humidity and air flow rate of indoor units; and (3) equipment capacity, performance curves and other related parameters were all obtained from the collaborative VRF manufacturer. All these realistic inputs enable thedecoupling ofthe simulation bias caused by the VRF algorithms from that caused by incorrect inputs, making the validation of VRF model more reliable.

The simulated and measured energy consumption datawerethen compared to determine the accuracy of the VRF model. The calibration criteria from ASHRAE Guideline 14-2002 [34]wereadopted for VRF model validation (Table 3). TheNormalized Mean Bias Error(NMBE) and Coefficient of Variation of the Root Mean Square Error (CVRMSE) weredetermined by comparing the predicted results $(\hat{y})$ with the measured data used for calibration $\left(y_{i}\right)$. NMBE and CVRMSE were calculated by Eq. 1 and 2, wherenrepresents the number of data used for in the calibration.

$$
\begin{gathered}
N M B E=\frac{\sum_{i=1}^{n}\left(y_{i}-\hat{y}_{i}\right)}{n \times \bar{y}} \times 100 \\
C V R M S E=100 \times \frac{\left[\sum_{i=1}^{n} \frac{\left(y_{i}-\hat{y}_{i}\right)^{2}}{n}\right]^{\frac{1}{2}}}{\bar{y}}
\end{gathered}
$$

Table 3: Calibration criteria from ASHRAE Guideline 14, with the Normalized Mean Bias Error (NMBE) and the Coefficient of Variation of the Root Mean Square Error (CVRMSE) [34].

The criteria can be applied to two time scales: monthly and hourly. Considering themonthly data, the model wasconsidered calibrated if the absolute value of NMBE wasless than 5\% and CVRMSE wasless than 15\%. Forhourly data, the criteria of NMBE and CVRMSE were $10 \%$ and $30 \%$, respectively [34]. 


\subsection{Validating thesimulation algorithms with the experimental data}

Validation of the VRF algorithms wasdone using the hourly data on a daily basis, as the measured data from the Daikin monitoring system and the house's separate monitoring system were compiled and pre-processedper day. In this paper,17 typical cooling days during June to September 2014 wereselected for validation of the cooling operation, and 10 typical heating days during January to March 2015 wereselected for validation of the heating operation.

\subsubsection{Validating the results from the cooling operations}

For validation, the energy use of the VRF system in the Caleb house iscompared with the simulated results using the new VRF model for 17 typical cooling days. Figure 5 shows a nearly perfect fit between the measured and simulated hourly VRF energy use in cooling mode.From the hourly comparison pattern, the new VRF model proved to be fairly accurate inpredicting the energy use variation trend, including capturing the peaks.Figure 6 showsthe error associated with the simulated daily energy use is within the range of $\pm 10 \%$. Figures 5 and 6indicate that the simulated and measured VRF energy use matched well for both the hourly and daily scale.

Figure 5: Hourly comparison between measured and simulated VRF energy use in cooling mode: new VRF model

Figure 6: Errors of daily energy use in cooling mode: new VRF model

The results indicate that the daily total measured VRF energy use is $87.5 \mathrm{kWh}$, about a $2 \%$ difference from the daily total simulated VRF energy use of $89.9 \mathrm{kWh}$. Using the hourly criteria from the ASHRAE Guideline14-2002 [34], the NMBE is $2.8 \%$ and the CVRMSE is $14.6 \%$, all within anacceptable criteria range. Therefore, the new VRF algorithms in cooling mode can be considered validated by the field test data.

\subsubsection{Validating the results from the heating operations}


Likewise, the energy use of the VRF system is compared with the simulated result in 10 typical heating days. Similar to the cooling mode, Figure 7 shows good agreement between the measured and simulated hourly VRF energy use in heating mode. The errors of the simulated daily energy use in heating mode are all within the range of $\pm 10 \%$, showing a good fit with the daily data as well (Figure 8).

Figure 7:Hourly comparison between measured and simulated VRF energy use in heating mode: new VRF model

Figure 8: Errors of daily energy use in heating mode: new VRF model

The daily total measured VRF energy use is $57.5 \mathrm{kWh}$ and the daily total simulated VRF energy use is $54.9 \mathrm{kWh}$. Using the hourly criteria from the ASHRAE Guideline [34], the NMBE is $-4.5 \%$ and the CVRMSE is $13.0 \%$. This is within the acceptable criteria range shown in Table 3. Therefore,the new VRF algorithms in heating mode can be considered validated by the field test data.

\section{Discussion}

\subsection{A comparison of simulation results between the new and existing VRF models in EnergyPlus}

The simulation accuracy of the new VRF model wascompared with the existing VRF model in EnergyPlus Version 7.2 using the same time periodas described in Section 3.The existing VRF model in EnergyPlus Version7.2 was also used to simulate the energy consumption of the VRF system in the Caleb house. The input cooling/heating loadsare the same for both simulations. Though the input data formats(IDFs) for the VRF system are different, they are describing the same system. Figure 9 shows the comparison between the measured and simulated VRF energy use in the cooling mode with Figure 10 presenting the errorassociated with the daily energy use for the cooling mode. Similarly, Figure 11 shows the comparison between the measured and 
simulated VRF energy use in the heating mode with Figure 12 presenting the errorassociated with the daily energy use for theheating mode. The results indicate that compared with the new VRF model, the existing VRF model is not as capable of predictingthe hourly energy use variations in either the cooling or heating mode. This becomes especially prevalent when comparing thepeak behavior. In terms of the daily total energy consumption, the errors of simulated results in two operation modes are beyond the $\pm 10 \%$ threshold, which indicates an inadequate match in daily scale. Moreover, the accuracy of the existing VRF model is unable tocomply withthe ASHRAE calibration criteria (Table 4).

Figure 9: Hourly comparison between the measured and simulated VRF energy use in cooling mode: existing VRF model in EnergyPlus Version 7.2

Figure 10: Errors of daily energy use in cooling mode: existing VRF model in EnergyPlus Version 7.2

Figure 11: Hourly comparison between the measured and simulated VRF energy use in heating mode: existing VRF model in EnergyPlus Version 7.2

Figure 12: Errors of daily energy use in heating mode: existing VRF model in EnergyPlus Version 7.2

Table 4: Calibration results of the existing VRF model in EnergyPlus Version 7.2 during the measured days

Taking a closer look at the comparison patterns between the simulated results using both the new and existing VRF models and the measure data, it can be noted from Figure 13 that: (1) two considerablepeaks mismatch (Areas A and B) happened because one indoor unit was operating for only five minutes and was then turned off. The inlet/outlet temperature and humidity varied significantly due to the start-up fluctuation, leading to a big measurement error of the cooling load for such a short period (about $5 \mathrm{~min}$.), so the simulated energy consumption and the measured data has a sever mismatch; (2) there is a significant gap between the simulated energy use from the existing VRF model and the measured data under low Part Load Ratio (PLR), 
where the main improvement of the new VRF model is indicated (Areas C and D); (3) there are still places that the new VRF model can improve, such as the capability to better simulate the energy consumption during the startup period (Areas $\mathrm{E}$ andF), and the elimination of some unexpected spikes when the status of the VRF system is fluctuated(Areas G and H).

Figure 13: Comparison of simulated energy use of both the new and existing VRF models and the measured data by minute

\subsection{Future plans}

Built upon the developed VRF Heat Pump (VRF-HP) model, a new VRF Heat Recovery (VRF-HR) model is being developed. The VRF-HR system is similar to a VRF-HP system except that it handles simultaneous cooling for some zones and heating for others. The VRF-HR model will be validated usingmeasured data from field testsin an office building. In addition, more features will be added to the simulation of the VRF systems in EnergyPlus. One of these features could include a demand response strategy todirectly slow down the compressor in the outdoor unit of a VRF system to reduce the electricity demand during peak periods.

\section{Conclusion}

Anew VRF model for heat pump modeoperation was developed and implemented in EnergyPlus. The model was validated using the field test data from a California house. The new features of the VRF-HP model include: (1)introduction of the component-level curves instead of overall curves for the entire system, (2) variable evaporating and condensing temperatures in the indoor and outdoor units, (3) variable fan speed based on the temperature and zone load in the indoor unit, (4) a physics model to calculate the thermal loss through the refrigerant piping network considering the variations of refrigerant flow rate and operational conditions. The new 
VRF-HP model enables the potential simulation of demand response of VRF systems by directly slowing down the speed of compressors in the outdoor units with invertertechnology.

Field testing of theVRF system in a typical California house was performed to collect data for model test and validation. The comparison between simulated and measured VRF performance datashowsexceptional compliance based on the criteria of ASHRAE Guideline 14. Therefore, the new VRF model can represent the actual performance of the VRF system accurately. This can support code compliance credits toward the use of VRF systems, as well as utilities incentive programs for VRF technologies.

\section{Acknowledgements}

The LBNL team thanks Daikin US Corporation and Daikin Industries LTD for the opportunity and financial support of this work. This work was also supported by the Assistant Secretary for Energy Efficiency and Renewable Energy, Building Technologies Program, of the U.S. Department of Energy under Contract No. DE-AC02-05CH11231.

\section{References}

[1] IEA, Key world energy statistics, 2009.

[2] Pe'rez-Lombard L, Ortiz J, Pout C, A review on buildings energy consumption information, Energy and Buildings 40 (2008) 394-398.

[3] Yang L, Yan H, JLam JC, Thermal comfort and building energy consumption implications A review,Applied Energy 115 (2014) 164-173.

[4] Lam JC, Wan KKW, Cheung KL, An analysis of climatic influences on chiller plant electricity consumption,Applied Energy 86 (2009) 933-940. 
[5] Lam TNT, Wan KKW, Wong SL, Lam JC, Impact of climate change on commercial sector air conditioning energy consumption subtropical Hong Kong,Applied Energy 87 (2010) $2321-2327$.

[6] Chung W, Review of building energy-use performance benchmarking methodologies,Applied Energy 88 (2011) 1470-1479.

[7] Lam K, Zhang R, Wang H, etc. Development of web-based information technology infrastructures and regulatory repositories for green building codes in China (iCodes). Building Simulation 6 (2013) 195-205.

[8] Chua KJ, Chou SK, Yang WM, Yan J, Achieving better energy-efficient air conditioning - a review of technologies and strategies,Applied Energy 104 (2013) 87-104.

[9] Aynur TN, Variable Refrigerant Flow Systems: A Review,Energy and Buildings 42 (2010) $1106-1112$.

[10] Goetzler W, Variable refrigerant flow systems, ASHRAE Journal (2007) 24-31.

[11] Amarnath A, Blatt M,Variable refrigerant flow: where, why, and how,EngineeredSystems (2008) 54-60.

[12] Liu X, Hong T, Comparison of energy efficiency between variable refrigerant flow systems and ground source heat pump systems,Energy and Buildings 42 (2010) 584-589.

[13] Amarnath A. and Blatt M. 2008, Variable Refrigerant Flow: An Emerging Air Conditioner and Heat Pump Technology, in: Proceedings of the 2008 ACEEE Summer Study on Energy Efficiency in Buildings, Pacific Grove, CA, Aug 17-22, 2008.

[14] Karunakaran R, Iniyan S, Goic R, Energy efficient fuzzy based combined variable refrigerant volume and variable air volume air conditioning system for buildings, Applied Energy 87 (2010) 1158-1175. 
[15] Aktacir MA, Büyükalaca O, Y1lmaz T, A case study for influence of building thermal insulation on cooling load and air-conditioning system in the hot and humid regions,Applied Energy 87 (2010) 599-607.

[16] Dyer M, Approaching 20 years of VRF in the UK, Modern Building Services, June 2006 (http://www.modbs.co.uk/news/fullstory.php/aid/2127/Approaching_20_years_of_VRF_in_the_UK.html).

[17] Zhou YP, Wu JY, Wang RZ, Shiochi S,Energy simulation in the variable refrigerant flow air-conditioning system under cooling conditions,Energy and Buildings 39 (2007) 212-220.

[18] Zhou YP, Wu JY, Wang RZ, Li YM, Shiochi S,Development and experimental investigation of the variable-refrigerant-flow (VRF) air conditioning system in EnergyPlus, in: International Congress of Refrigeration, Beijing, China, 2007.

[19] Zhou YP, Wu JY, Wang RZ, Shiochi S, Li YM,Simulation and experimental validation of the variable-refrigerant-volume (VRV) air-conditioning system in EnergyPlus, Energy and Buildings 40 (2008) 1041-1047.

[20] Aynur TN, Hwang Y, Radermacher R, Simulation comparison of VAV and VRF air conditioning systems in an existing building for the cooling season, Energy and Buildings 41 (2009) 1143-1150.

[21] Li YM, Wu JY, Shiochi S, Experimental validation of the simulation module of the water-cooled variable refrigerant flow system under cooling operation,Applied Energy 87 (2010) 1513-1521.

[22] Roth KW, Westphalen D, Dieckmann J, Hamilton SD, Goetzler W, Energy consumption characteristics of commercial building HVAC systems Volume III: Energy saving potential, Reference No: 68370-00, 2001, TIAX LLC, Cambridge, MA, USA. 
[23] Zhu YH, Jin X, Du Z, Fang X, Fan B,Control and energy simulation of variable refrigerant flow air conditioning system combined with outdoor air processing unit, Applied Thermal Engineering 64 (2014) 385-395.

[24] Tu Q, Feng Z, Mao S, Dong K, Xiao R, Song W, Heating control strategy for variable refrigerant flow air conditioning system with multi-module outdoor units, Energy and Buildings 42 (2010) 2021-2027.

[25] Zhu Y, Jin X, Du Z, Fan B, Fu S, Generic simulation model of multi-evaporator variable refrigerant flow air conditioning system for control analysis, International Journal of Refrigeration 36 (2013) 1602-1615.

[26] Aynur TN, Hwang Y, Radermacher R,Field performance measurements of a VRV $\mathrm{AC} / \mathrm{HP}$ system, in: 11th International Refrigeration and Air Conditioning Conference at Purdue, West Lafayette, IN, USA, (2006), pp. 1-8.

[27] Li YM, Wu JY, Shiochi S,Modeling and energy simulation of the variable refrigerant flow air conditioning system with water-cooled condenser under cooling conditions, Energy and Buildings 41 (2009) 949-957.

[28] Raustad R,A variable refrigerant flow heat pump computer model in EnergyPlus, ASHRAE Transactions (2013), 119(1):1-9.

[29] Sharma C, Raustad R,Compare energy use in variable refrigerant flow heat pumps field demonstration and computer model, in: ASHRAE Annual Conference, Denver, Colorado, June 22-27, 2013. DE-13-C072.

[30] Hong T, Eley CN, Kolderup E, Two DOE-2 functions, in: IBPSA Building Simulation Conference, Canada, 2005. 
[31] DOE, EnergyPlus Documentation, Engineering Reference version 8.4, U.S. Department of Energy, Washington D.C. 2015.

[32] Crawley DB, Lawrie LK, Winkelmann FC, Buhl WF, et al,EnergyPlus: creating a newgeneration building energy simulation program, Energy and Buildings 33 (2001) 319-331.

[33] ASHRAE, ANSI/ASHRAE Standard 140-2014: Standard Method of Test for the Evaluation of Building Energy Analysis Computer Programs,ASHRAE, Atlanta, 2014.

[34] California Energy Commission, Building energy efficiency standards for residential and non-residential buildings (Title 24), 2005.

[35] ASHRAE,ANSI/ASHRAE Guideline 14-2002: Measurement of Energy and Demand Savings, ASHRAE, Atlanta, 2002. 


\section{Appendix A}

The new VRF algorithms are described in details below, including the models of both the indoor and outdoor units. Only the cooling mode algorithmisdescribed here for brevity purposes. Figure 14 shows the holistic logic of the new VRF algorithm at cooling mode.Please refer to the current EnergyPlus Engineering Reference for more details on the heating mode algorithm [30].

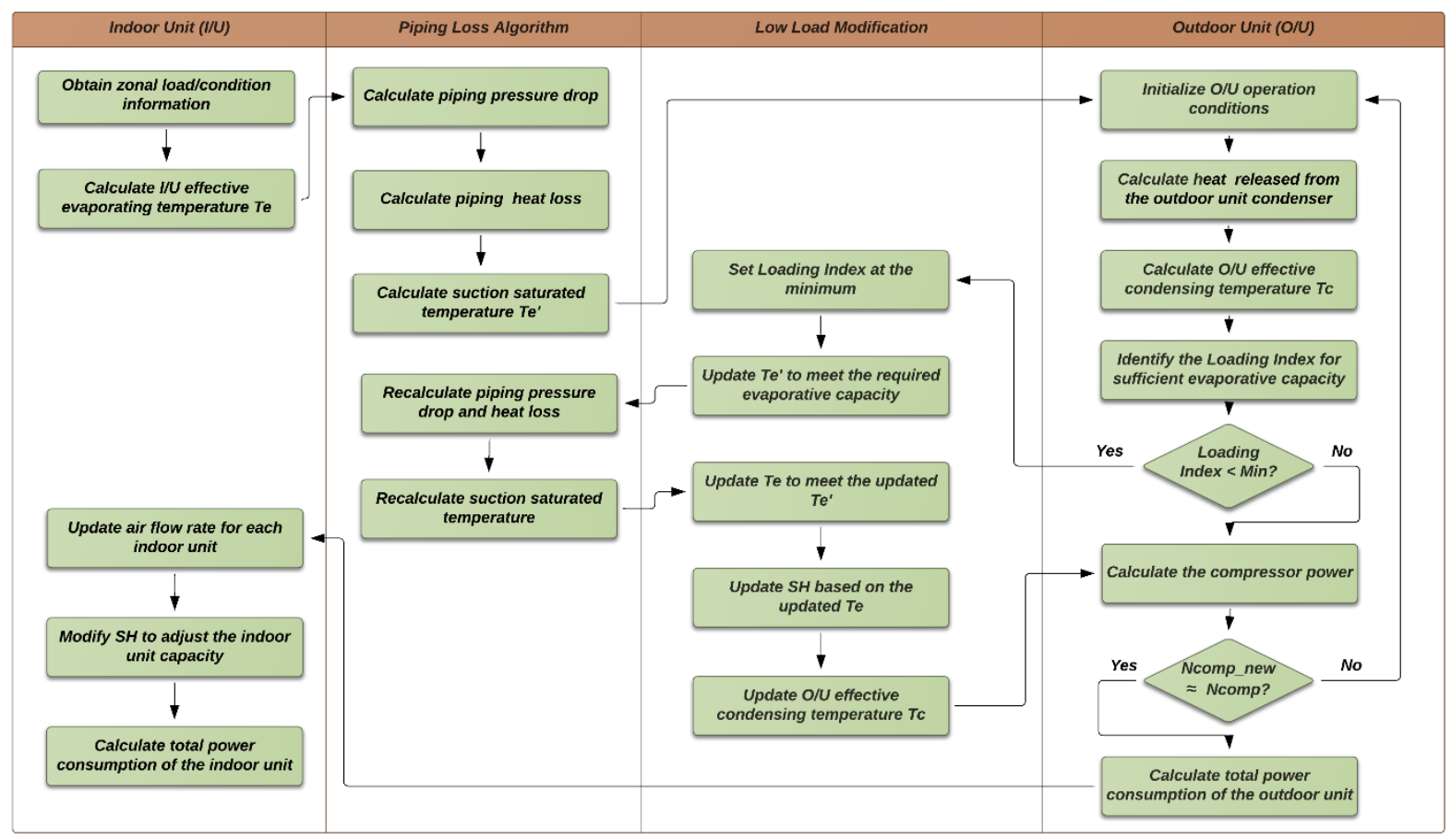

Figure 14: Schematic chart of the new VRF-HP algorithm at cooling mode

\section{A.1 Modeling of the indoor unit (I/U) - Part I}

\section{Step 1.1: Obtaining zonal load/condition information}

Obtain the following information for each zone from the zone modules within EnergyPlus: (1) zone sensible loads $Q_{i n, \text { sensible }},(2)$ zone total loads $Q_{i n, \text { total }},(3)$ indoor air temperature $T_{i n},(4)$ indoor air humidity ratio $W_{i n}$. The operation mode of the VRF system can therefore be determined from $Q_{\text {in, sensible. }}$

\section{Step 1.2: Calculate effective evaporating temperature}

Assume the coil air flow rate is at the maximum, the temperature of the air entering each indoor unit can be calculated by:

$$
T_{\text {coil }, \text { in }}=T_{i n}+Q_{\text {fan }} /\left(G_{a, \text { rate }} \times c_{p} \times \rho_{\text {in }}\right)
$$

The supply air temperature $T_{\text {out }}$ can be calculated by:

$$
T_{\text {out }}=T_{\text {coil,in }}-Q_{\text {in,sensible }} /\left(G_{a, \text { rate }} \times c_{p} \times \rho_{\text {in }}\right)
$$

The coil surface air temperature $T_{f s}$ can be calculated by: 


$$
T_{f s}=T_{\text {coilin }}-\left(T_{\text {coilin }}-T_{\text {out }}\right) /(1-B F)
$$

The required evaporating temperature $T e_{r e q}$ for the associated indoor unit can be obtained via:

$$
T e_{r e q}=T_{f s}-\left[A_{c} \cdot\left(S H / S H_{r e f}\right)^{2}+B_{c} \cdot\left(S H / S H_{r e f}\right)+C_{c}\right]
$$

The effective evaporating temperature in the cooling mode can then be calculated by:

$$
T e=\min \left\{\max \left[\operatorname{mi} \mathrm{n}\left(T e_{r e q, i}\right), T e_{\min }\right], T e_{\max }\right\}
$$

\section{A.2 Modeling of the outdoor unit $(\mathrm{O} / \mathrm{U})$}

\section{Step 2.1: Piping loss calculation in the cooling mode}

Piping loss occurs when the refrigerant flows through the main pipe connecting the indoor and outdoor units. It has two components, the refrigerant pressure drop and heat loss. It affects the VRF system operation in several ways. First, the heat loss creates an extra load to the system and leads to higher energy consumptions. Second, the pressure drop and heat loss changes the operational conditions of the compressor (i.e., compressor suction pressure and compressor suction temperature) and thus affects its operational performance. Therefore, the piping loss calculation is critical for the analysis of the whole system.

Note that the change of compressor operational conditions may lead to different control strategies of the system, which in reverse affects the amount of piping loss. So the piping loss analysis and system performance analysis are coupled together. Numerical iterations are designed to address the coupling effect, as described below.

Calculate the refrigerant flow rate for each indoor unit using assumed $h_{\text {Hexin }}$ :

$$
G_{i}=Q_{i} /\left(h_{\text {Hexout }, i}-h_{\text {Hexin }}\right)
$$

Enthalpy of refrigerant leavingeach indoor unit $h_{\text {Hexout }, \text { can }}$ be calculated using refrigerant thermodynamic property equations $f_{g_{-} h}\left(P_{e}, T_{e}+S H_{i}\right)$.

The enthalpy of the refrigerant in the main loop $h_{\text {Hexout }}$ can be obtained by calculating the weighted average of the enthalpy of the refrigerant in each indoor unit:

$$
\begin{gathered}
h_{\text {Hexout }}=\sum\left(h_{\text {Hexout }, i} \times G_{i} / G_{\text {tot }}\right) \\
G_{\text {tot }}=\sum G_{i}
\end{gathered}
$$

Given $h_{\text {Hexout }}$ and $P_{e}=f_{s_{-} p}\left(T_{e}\right)$, the following dimensionless quantities describing the refrigerant flow state can be obtained:

$$
\begin{gathered}
R e=G_{\text {to }} / 3600 /\left(0.25 \times \pi \times D^{2}\right) \times D / \mu \\
\operatorname{Pr}=\mu \times f_{g_{-} C p}\left(P_{e}, h_{\text {Hexout }}\right) \times 0.001 / f_{g_{-} \lambda}\left(P_{e}, h_{\text {Hexout }}\right) \\
N u=0.023 \times \operatorname{Re}^{0.8} \times \operatorname{Pr}^{0.3} \\
S t=N u /(\operatorname{Re} \times \operatorname{Pr})
\end{gathered}
$$


Then the piping pressure loss $\Delta P_{\text {pipe }}$ can be obtained using the above dimensionless quantities:

$\Delta P_{\text {pipe }}=8 \times S t \times P r^{2 / 3} \times L / D \times f_{g_{-} \rho}\left(P_{e}, h_{\text {Hexout }}\right) \times V^{2} / 2+H \times f_{g_{-} \rho}\left(P_{e}, h_{\text {Hexout }}\right) \times 9.8066$

The suction saturated temperature $T_{e}$ ' (i.e., saturated vapor temperature corresponding to the compressor suction pressure) can be obtained via refrigerant thermodynamic property equations:

$$
T_{e}{ }^{\prime}=f_{s_{-}} t\left(P_{e^{-}} \Delta P_{\text {pipe }}\right)
$$

The heat loss through the pipe can be obtained via:

$$
\begin{gathered}
k_{1}=N u \times f_{g_{-} \lambda}\left(P_{e}, h_{\text {Hexout }}\right) \\
k_{2}=2 \times \lambda_{i} / L n\left(1+2 \times w_{i} / D\right) \\
k_{3}=h \times\left(D+2 \times w_{i}\right) \\
Q_{\text {pipe }}=(\pi \times L) \times\left(T_{a}-T_{\text {Hexout }}\right) /\left(1 / k_{1}+1 / k_{2}+1 / k_{3}\right)
\end{gathered}
$$

Note that $Q_{\text {pipe }}$ is calculated using an assumed $h_{\text {Hexin }}$. Its value affects the compressor operation calculations as shown in Step 2.2 2.6 and may change the value of condensing temperature $T_{c}$. This leads to an updated $h_{\text {Hexin }}=f\left(P_{c}, T_{c^{-}} S C\right)$. If the difference between the calculated $h_{\text {Hexin }}$ and the assumed $h_{\text {Hexin }}$ is higher than the assigned tolerance $(5 \%)$, a new round of iteration is performed using the calculated $h_{\text {Hexin }}$.

\section{Step 2.2: Initialize $\mathrm{O} / \mathrm{U}$ operation conditions}

The compressor operation is coupled with a number operational parameters, which makes it difficult to obtain an analytical solution. In the proposed algorithm, an iterative approach is designed to obtain the energy consumption of the compressor (Step $2.2-2.6$ ).

For the first iteration,

- Initialize outdoor unit $S C$ with the reference value

- initialize the compressor power $N_{\text {comp }}$ with the value calculated from the reference COP (e.g., 3.5):

$$
N_{\text {comp }}^{\prime}=\sum Q_{\text {in,total }, i} / C O P
$$

For the following iterations,

- Initialize $S C$ with the calculated value in the previous iteration

- Initialize the compressor power $N_{\text {comp }}$ with the calculated value in the previous iteration

The heat rate released from the outdoor unit can be calculated by:

$$
Q_{\text {out }}=\sum Q_{\text {in,total }, i}+N_{\text {comp }}+Q_{\text {pipe }}
$$

Step 2.3: Calculate O/U effective condensing temperature

a. Calculate the required coil surface air temperature $T_{f s}{ }^{\prime}$ for the outdoor unit.

The temperature of the air leaving the outdoor unit $T_{\text {out }}{ }^{\prime}$ can be calculated by: 


$$
T_{\text {out }}{ }^{\prime}=T_{\text {in }}{ }^{\prime}+Q_{\text {out }} /\left(G_{a, \text { rate }}{ }^{\prime} \times c_{p} \times \rho_{\text {in }}{ }^{\prime}\right)
$$

The condenser surface temperature $\mathrm{T}_{\mathrm{fs}}{ }^{\prime}$ can be calculated by:

$$
T_{f s}{ }^{\prime}=T_{\text {in }}{ }^{\prime}+\left(T_{\text {out }}{ }^{\prime}-T_{\text {in }}{ }^{\prime}\right) /\left(1-B F_{c}{ }^{\prime}\right)
$$

b. Calculate required condensing temperature for the outdoor unit $\mathrm{Tc}_{\mathrm{req}}$ and then the effective condensing temperature $\mathrm{T}_{\mathrm{c}}$ (between $42-46^{\circ} \mathrm{C}$ )

$$
T c=T_{f s}{ }^{\prime}+\left[A_{h} \cdot\left(S C / S C_{r e f}\right)^{2}+B_{h} \cdot\left(S C / S C_{r e f}\right)+C_{h}\right]
$$

\section{Step 2.4: Calculate required Loading Index}

Loading Index is used to describe the operational mode of the compressor system. The first index represents minimal capacity operation, while the last index represents full capacity operation. The required Loading Index can be calculated by the following procedures.

a. Calculate the evaporative capacity at a variety of Loading Index:

$$
\begin{aligned}
Q_{r p s} & \\
& =C_{c a p, \text { system }} \times\left(r_{1}+r_{2} \times T_{c}+r_{3} \times T_{e}{ }^{\prime}+r_{4}\right. \\
& \left.\times T_{c}{ }^{2}+r_{5} \times T_{c} \times T_{e}{ }^{\prime}+r_{6} \times T_{e}{ }^{\prime 2}\right)
\end{aligned}
$$

b. Find the rps range that covers the required evaporative capacity $\mathrm{Q}_{\mathrm{rps}, \mathrm{modify}}$.

$$
\begin{aligned}
& Q_{r p s, \text { modify }}=C_{\text {cap ,operation }} \times\left(\sum Q_{\text {in,total }}+Q_{\text {pipe }}\right) \\
& C_{c a p, \text { operation }}=C_{c a p, \text { density }} \times C_{c a p, \text { ent halpy }} \\
& C_{\text {cap }, \text { density }}=\rho_{\text {test }} / \rho_{\text {real }} \\
& C_{\text {cap ,ent halpy }}=\frac{h_{\text {Evapout }, \text { test }}-h_{\text {Evapin , test }}}{h_{\text {Compin }, \text { real }}-h_{\text {Hexin }, \text { real }}} \\
& h_{\text {Compin }, \text { real }}=h_{\text {Hexout,real }}+Q_{\text {pipe }} / G_{\text {tot }}
\end{aligned}
$$

c. Calculate the rps that meets the required capacity by interpolation.

d. If the calculated $r p s$ is lower than the minimum rps (e.g. 18rps) go to Step 2.5, otherwise skip Step 2.5 and directly go to Step 2.6.

Step 2.5: Modify evaporating temperature to further reduce outdoor unit capacity

If the calculated rps is lower than the minimum rps (e.g. 18rps), it means that the zone cooling load is even lower than the system evaporative capacity corresponding to the minimum compressor speed. In this situation, the evaporating temperature $T e$ as well as the superheating degree $S H$ is modified to further reduce the outdoor unit capacity. More specifically: 
a. Set rpsat its minimum value (e.g., $18 \mathrm{rps}$ ).

b. Update $T e^{\prime}$ to meet the required evaporative capacity, using equations described in Step 2.4a.

c. Update $T e$ to meet the updated $T e^{\prime}$. Note that due to the $T e$ updates, the refrigerant state and flow rate are changed and thus the piping loss analysis should also reperformed (Step 2.1). So is the calculation of $C_{\text {cap,operation }}$ (Step 2.2-2.3).

d. $S H$ can be updated based on the updated Te, using the equations shown in Step 1.2.

Step 2.6: Calculate the compressor power

a. Calculate the compressor power at a variety of loading index using the following equation.

$$
N_{\text {comp }, r p s}=c_{1}+c_{2} \times T_{c}+c_{3} \times T_{e}{ }^{\prime}+c_{4} \times T_{c}{ }^{2}+c_{5} \times T_{c} \times T_{e}{ }^{\prime}+c_{6} \times T_{e}{ }^{2}
$$

b. According to the rps range determined, calculate the compressor power $N_{\text {comp }}$ by interpolation.

c. Compare the calculated $N_{\text {comp }}$ above with the initialized $N_{\text {comp }}{ }^{\prime}$ in Step 2.2:

- If $N_{\text {comp }}{ }^{\prime}-N_{\text {comp }}>\delta$ then go to Step 2.2 for a new round of iteration

- $\quad$ Else, end the iteration and go to Step 2.7

Step 2.7: Total power consumption of the outdoor unit

Calculate the total electric power consumption by the outdoor unit:

$$
N_{\text {out }}=N_{\text {fan }}+N_{\text {comp }} / e_{i n v}
$$

\section{A.3 Modeling of the indoor unit (I/U) - Part II}

Step 3.1: Update air flow rate for each indoor unit

a. Calculate coil surface temperature for each indoor unit:

$$
T_{f s}=T_{e}+\left[A_{c} \cdot\left(S H / S H_{r e f}\right)^{2}+B_{c} \cdot\left(S H / S H_{r e f}\right)+C_{c}\right]
$$

b. Calculate the enthalpy of the air at the coil surface, $\mathrm{H}_{\mathrm{fs}}$ :

$$
\begin{array}{ll}
\text { if } \quad T_{f s}<T_{98 \%}, W_{i n} & \text { then } H_{f s}=f\left(T_{f s}, 98 \%\right) \\
\text { if } \quad T_{f s} \geq T_{98 \%}, W_{i n} & \text { then } H_{f s}=f\left(T_{f s}, W_{i n}\right)
\end{array}
$$

c. Calculate the required air flow rate $\mathrm{G}_{\mathrm{a}}$ for each indoor unit:

$$
G_{a}=Q_{\text {in,total }} /\left[\left(H_{\text {coilin }}-H_{f_{s}}\right) \times(1-B F) \times \rho_{i n}\right]
$$

d. Decide whether to modify $\mathrm{SH}$ for further indoor unit capacity reduction

- $\quad$ if $G_{a}<G_{a, \min }$ (e.g., $0.7 \times \mathrm{G}_{\mathrm{a}, \text { rate }}$ ) go to Step 3.2. 
- $\quad$ Else, directly go to Step 3.3.

Step 3.2: Modify SH to adjust the indoor unit capacity

a. Set $G_{a}$ at its minimum value.

b. The required coil surface temperature $T_{f_{s}}$ can be determined as described in Step 1.2.

c. Given $T_{f s}$ and $T_{e}, S H$ can be determined using the equation shown in Step 1.3.

d. If $S H$ is greater than the maximum value (e.g., $15^{\circ} \mathrm{C}$ ), set $S H$ as the maximum. On/Off control strategy may be implemented when needed.

\section{Step 3.3: Total power consumption of the indoor unit}

The power consumption of the indoor unit comes from the fan operations. This can be calculated using the existing VAV fan model in EnergyPlus. Please refer to the current EnergyPlus Engineering Reference for more details [30].

\section{A.4 Additional energy consumption due to defrost and crankcase heater}

There may be additional energy consumption due to the defrost operation and crankcase heater operation. These components have no impact on the heat pump operations. The calculation methods in the existing VRF model are implemented to calculate such energy consumption [30].

\section{Nomenclature}

$B F \quad$ bypass factor [--]

$c_{p} \quad$ air heat capacity $[\mathrm{kJ} /(\mathrm{kg} \cdot \mathrm{K})]$

$C_{c a p} \quad$ evaporative capacity correction factor [--]

$C_{c a p, s y s t e m}$ evaporative capacity correction factor, describing the possible system configuration difference between test bed and real system (a constant value obtained from manufacturer data) [--]

$\mathrm{C}_{\text {cap,operation }}$ evaporative capacity correction factor, describing the operational difference between test cases and real cases (i.e., SH and SC) [--]

$\mathrm{C}_{\text {cap,density }}$ evaporative capacity correction factor, describing the variations of refrigerant density at test conditions and real operational conditions [--]

$\mathrm{C}_{\text {cap,enthalpy }}$ evaporative capacity correction factor, describing the variations of refrigerant enthalpy at test conditions and real operational conditions [--]

CVRMSE coefficient of variation of the root mean square error [\%]

$e_{i n v} \quad$ efficiency of the inverter of compressor [--]

$D \quad$ main pipe diameter $[\mathrm{m}]$

$e_{i n v} \quad$ efficiency of the inverter of compressor [--]

$f_{s_{-} p} \quad$ functions calculating the pressure of saturated refrigerant [--]

$f_{s_{-} t} \quad$ functions calculating the temperature of saturated refrigerant [--]

$f_{g_{-} C p} \quad$ functions calculating the specific heat of superheating refrigerant [--] 
$f_{g_{-} \lambda} \quad$ functions calculating the conductivity of superheating refrigerant [--]

$f_{g \_} \rho \quad$ functions calculating the density of superheating refrigerant [--]

$G_{i} \quad$ refrigerant flow rate for the ith indoor unit $[\mathrm{kg} / \mathrm{s}]$

$G_{\text {tot }}$ refrigerant flow rate in the main loop $[\mathrm{kg} / \mathrm{s}]$

$G_{a} \quad$ volumetric flow rate of the air $\left[\mathrm{m}^{3} / \mathrm{s}\right]$

$G_{a, \min }$ minimumvolumetric flow rate of the air $\left[\mathrm{m}^{3} / \mathrm{s}\right]$

$h \quad$ enthalpy of the refrigerant $[\mathrm{kJ} / \mathrm{kg}]$

$h_{\text {Hexin, real }}$ enthalpy of refrigerant entering the indoor unit at real conditions $[\mathrm{kJ} / \mathrm{kg}]$

$h_{\text {Hexout }, \text { real }}$ average enthalpy of refrigerant leaving the indoor units at real conditions $[\mathrm{kJ} / \mathrm{kg}]$

$h_{\text {Evapin,test }}$ enthalpy of refrigerant entering the evaporator at test conditions (It corresponds to $\mathrm{SC}$ at test condition(e.g., $\left.5^{\circ} \mathrm{C}\right)$ and $\left.\mathrm{Tc}\right)[\mathrm{kJ} / \mathrm{kg}]$

$h_{\text {Evapou,test }}$ enthalpy of refrigerant leaving the evaporator at test conditions (It corresponds to $\mathrm{SH}$ at test condition (e.g., $8^{\circ} \mathrm{C}$ ) and $\left.\mathrm{Te}\right)[\mathrm{kJ} / \mathrm{kg}]$

$h_{\text {Compin }}$ enthalpy of refrigerant entering the compressor $[\mathrm{kJ} / \mathrm{kg}]$

$H \quad$ height difference between the outdoor and indoor unit nodes of the main pipe [m]

$\mathrm{H}_{\text {coil,in }}$ enthalpy of the suction air of the indoor unit $[\mathrm{kJ} / \mathrm{kg}]$

$\mathrm{H}_{\mathrm{fs}} \quad$ enthalpy of the air at the indoor unit coil surface $[\mathrm{kJ} / \mathrm{kg}]$

$H_{f s}{ }^{\prime} \quad$ enthalpy of the air leaving the outdoor unit $[\mathrm{kJ} / \mathrm{kg}]$

$H_{\text {in }}{ }^{\prime} \quad$ enthalpy of the air entering the outdoor unit, i.e., outdoor air $[\mathrm{kJ} / \mathrm{kg}]$

$k_{i} \quad$ coefficients for the piping loss calculation [--]

$L \quad$ main pipe length [m]

$P_{c} \quad$ condensing pressure $[\mathrm{Pa}]$

$P_{e} \quad$ evaporating pressure $[\mathrm{Pa}]$

$\mathrm{Pr} \quad$ Prandtl number [--]

$P_{s} \quad$ compressor suction pressure $[\mathrm{Pa}]$

$N_{\text {comp }} \quad$ compressor power $[\mathrm{kW}]$

$N_{\text {comp }}^{\prime}$ assumed compressor power for the first iteration [kW]

$\mathrm{N}_{\text {comp, rps }}$ compress power corresponding to specific rotating speed [kW]

$\mathrm{Nu} \quad$ Nusselt number [--]

$N M B E$ normalized mean bias error[\%]

$N_{f a n} \quad$ electric power consumption by the outdoor fan [kW]

$N_{\text {out }} \quad$ total electric power consumption by the outdoor unit [kW]

$Q_{\text {fan }} \quad$ sensible heat released by fan $[\mathrm{kW}]$

$Q_{\text {in }} \quad$ cooling load of the $\mathrm{i}^{\text {th }}$ zone $[\mathrm{kW}]$

$Q_{\text {out }} \quad$ heat rate released from the outdoor unit [kW]

$Q_{r p s} \quad$ evaporative capacity corresponding to rps [kW]

$Q_{\text {pipe }}$ heat loss through the main pipe $[\mathrm{kW}]$

Re Reynolds number [--] 


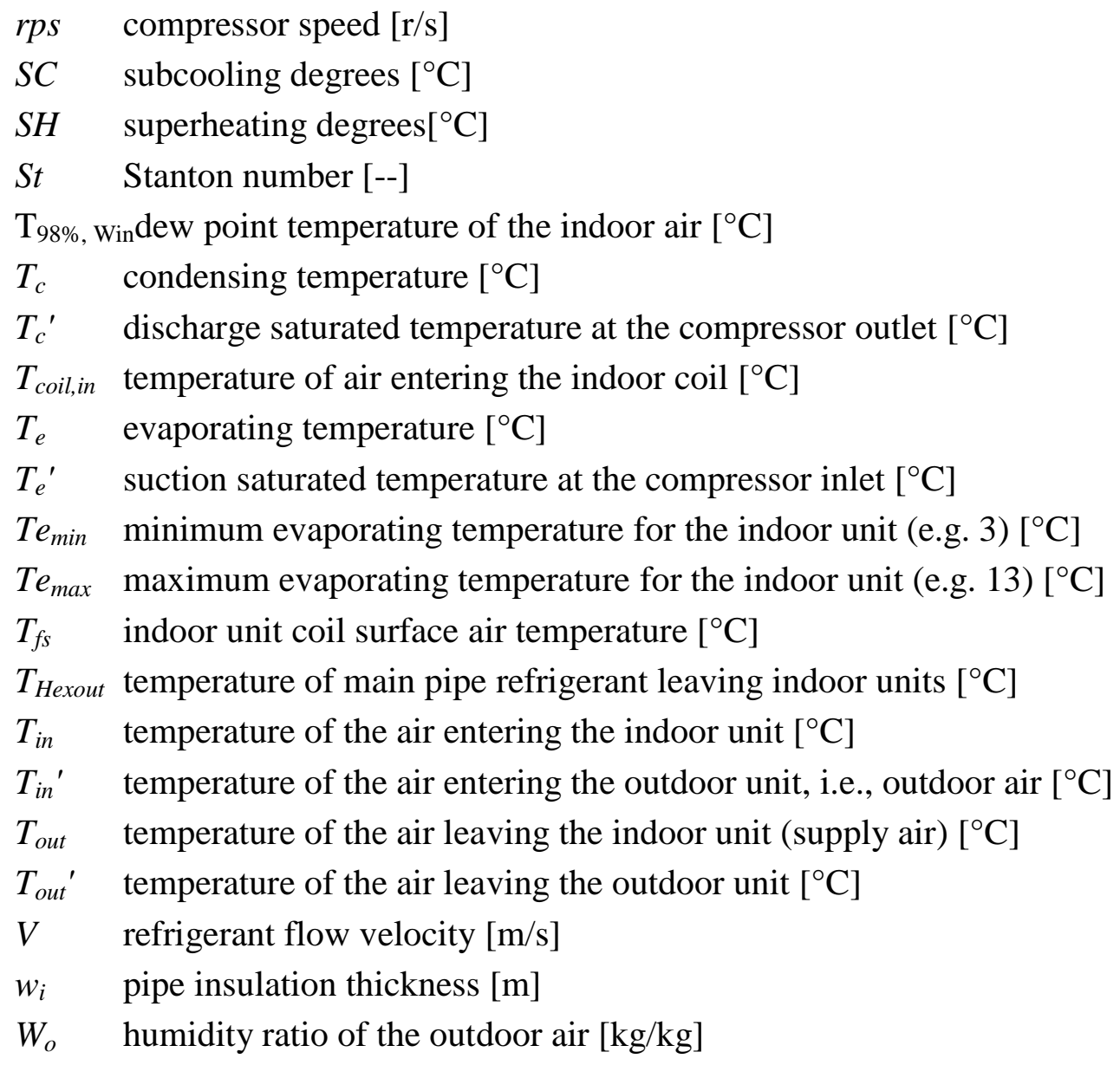

\section{Subscripts}

Hexin refrigerant entering the indoor unit

Hexout refrigerant leaving the indoor unit

$i \quad$ the $\mathrm{i}^{\text {th }}$ indoor unit

in indoor air environment

ref reference condition

req required values

sensible sensible cooling load

total total cooling load

\section{Greek letter notation}

$\rho_{\text {in }} \quad$ density of indoor air, $f_{\rho}\left(T_{i n}, W_{i n}\right)\left[\mathrm{kg} / \mathrm{m}^{3}\right]$

$\rho_{i n}{ }^{\prime} \quad$ air density at outdoor conditions, $f_{\rho}\left(T_{i n}{ }^{1}, W_{i n}{ }^{\prime}\right)\left[\mathrm{kg} / \mathrm{m}^{3}\right]$

$\Delta P_{\text {pipe }}$ pressure drop in the pipe $[\mathrm{Pa}]$

$\mu \quad$ viscosity of the refrigerant within the pipe [Pa-s] 


\section{Tables}

Table 1: Thermal properties of the envelope

\begin{tabular}{cccc}
\hline & Area $\left(\mathrm{m}^{2}\right)$ & $\mathrm{U}$-factor $\left(\mathrm{W} / \mathrm{m}^{2} \cdot \mathrm{K}\right)$ & $\mathrm{SHGC}$ \\
\hline Exterior Walls & 215 & 0.39 & \\
Roof & 74 & 1.03 & \\
& & & 0.3 \\
Exterior Windows & 31 & 1.99 & \\
\hline
\end{tabular}

Table 2. List of the Monitored Data Points

\begin{tabular}{ll}
\hline Category & Item \\
\hline Energy Use & (1) Total House kWh, (2) House AC Outdoor Condensing Unit \\
& $\mathrm{kWh},(3)$ House AC Indoor Unit kWh
\end{tabular}

Occupancy Simulator

(Internal heat and (1) Electric heaters kWh, (2) Humidifiers kWh

moisture loads)

Ambient

(1) Outdoor Ambient Temperature, (2) Outdoor Ambient Humidity,

(3) Wind Speed, (4) Horizontal Solar Radiation

(1) Thermostat Set Point, (2) Supply Air Temperatureand humidity,

(3) Return Air Temperatureand humidity, (4) Return Air humidity,

VRV system (5) Condensing Unit status (on/off), (6) Inlet refrigerant

Temperatureof indoor units, (7) Outlet refrigerant Temperatureof indoor units 
Table 3: Calibration criteria from ASHRAE Guideline 14, with the Normalized Mean Bias Error (NMBE) and the Coefficient of Variation of the Root Mean Square Error (CVRMSE) [33].

$$
\text { NMBE CVRMSE }
$$

\begin{tabular}{lll}
\hline Monthly & $\pm 5 \%$ & $15 \%$ \\
Hourly & $\pm 10 \%$ & $30 \%$ \\
& & \\
\hline
\end{tabular}

Table 4: Calibration results of the existing VRF model in EnergyPlus Version 7.2 during the

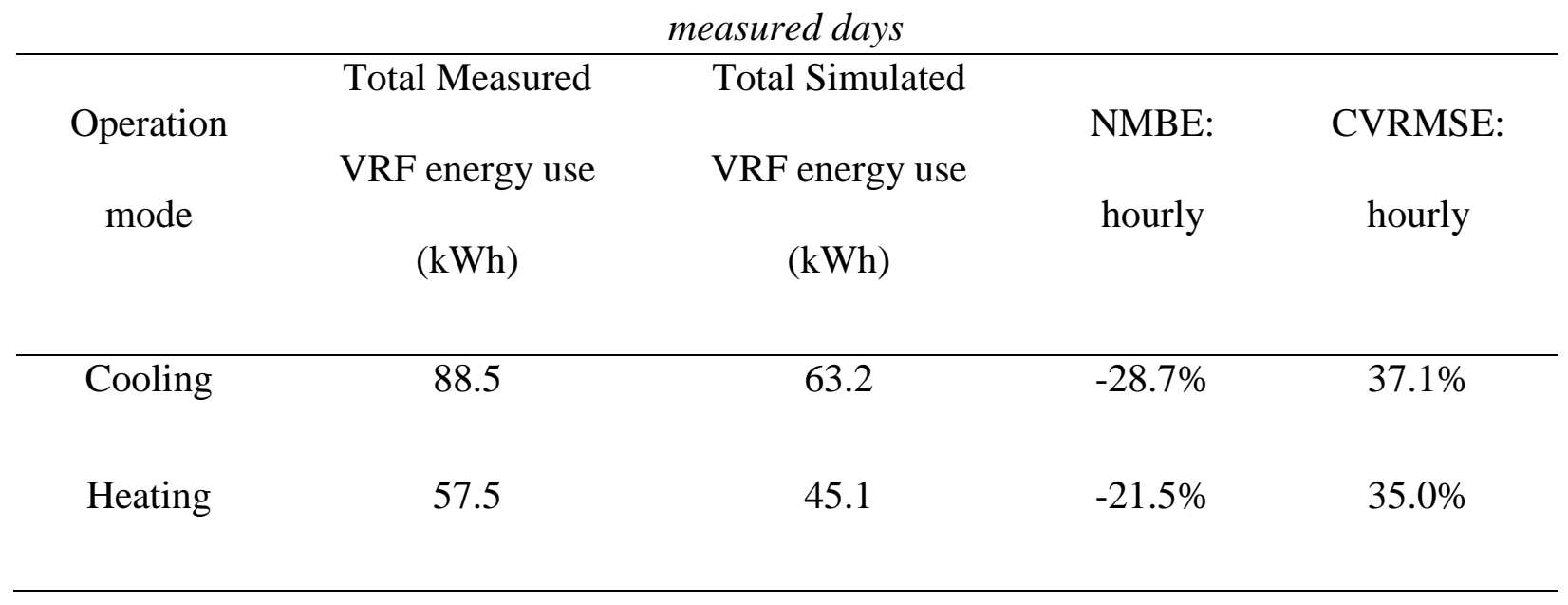




\section{Figures}

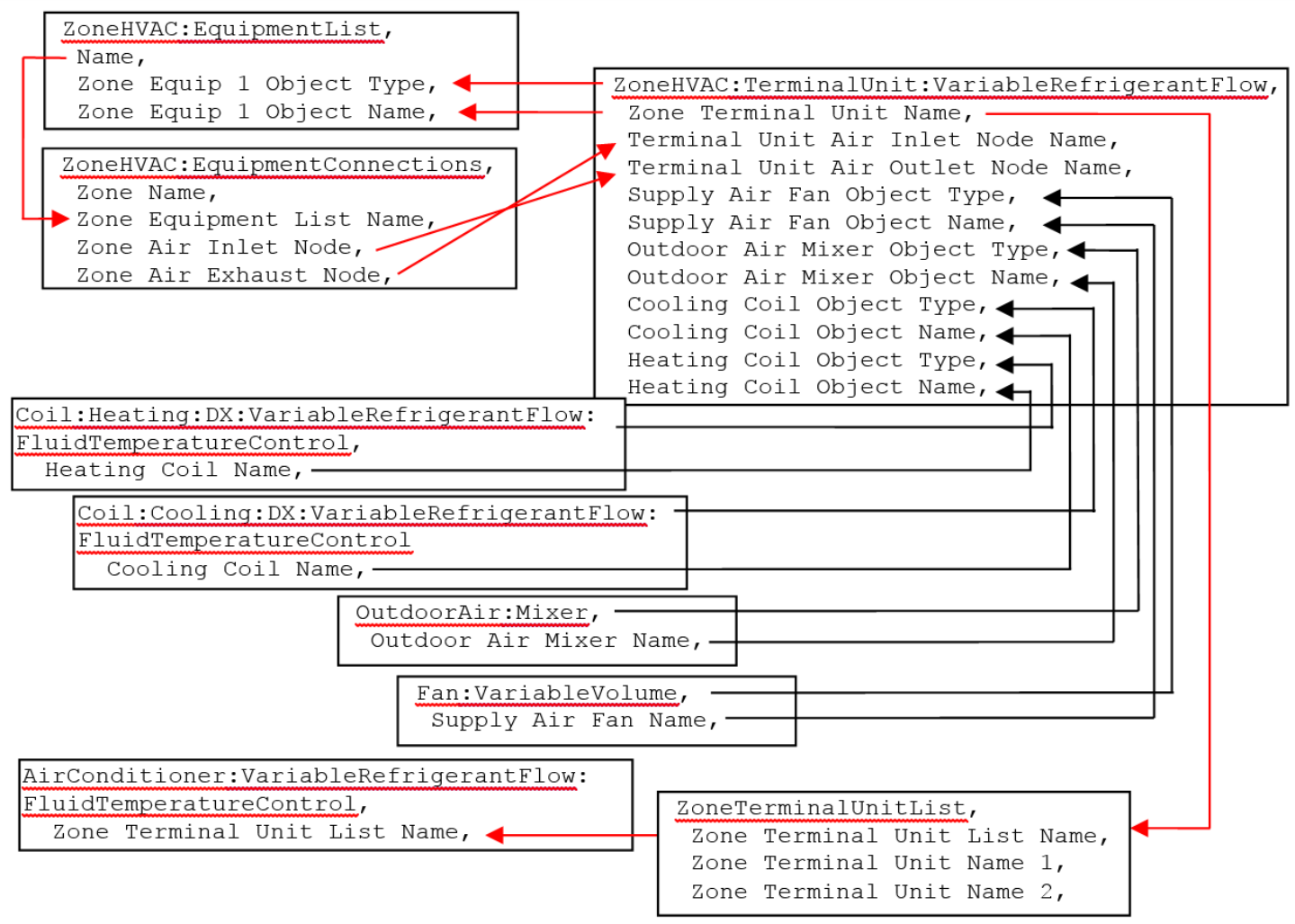

Figure 1: VRF system objects and their connections in EnergyPlus(adapted from [30]) 


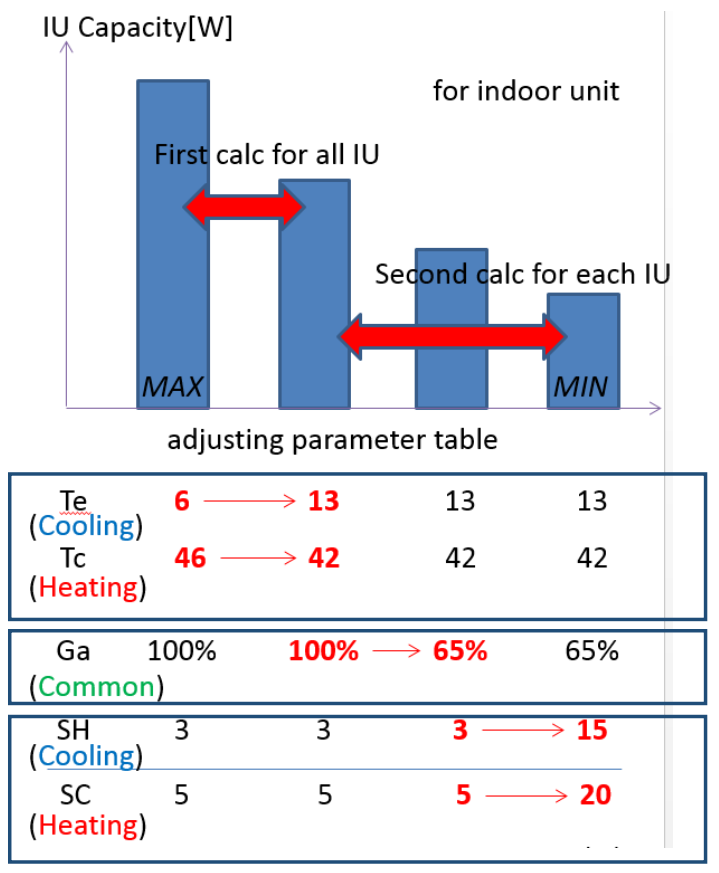

Figure 2: Multi-stage control strategy to adjust the system capacity during low load conditions 

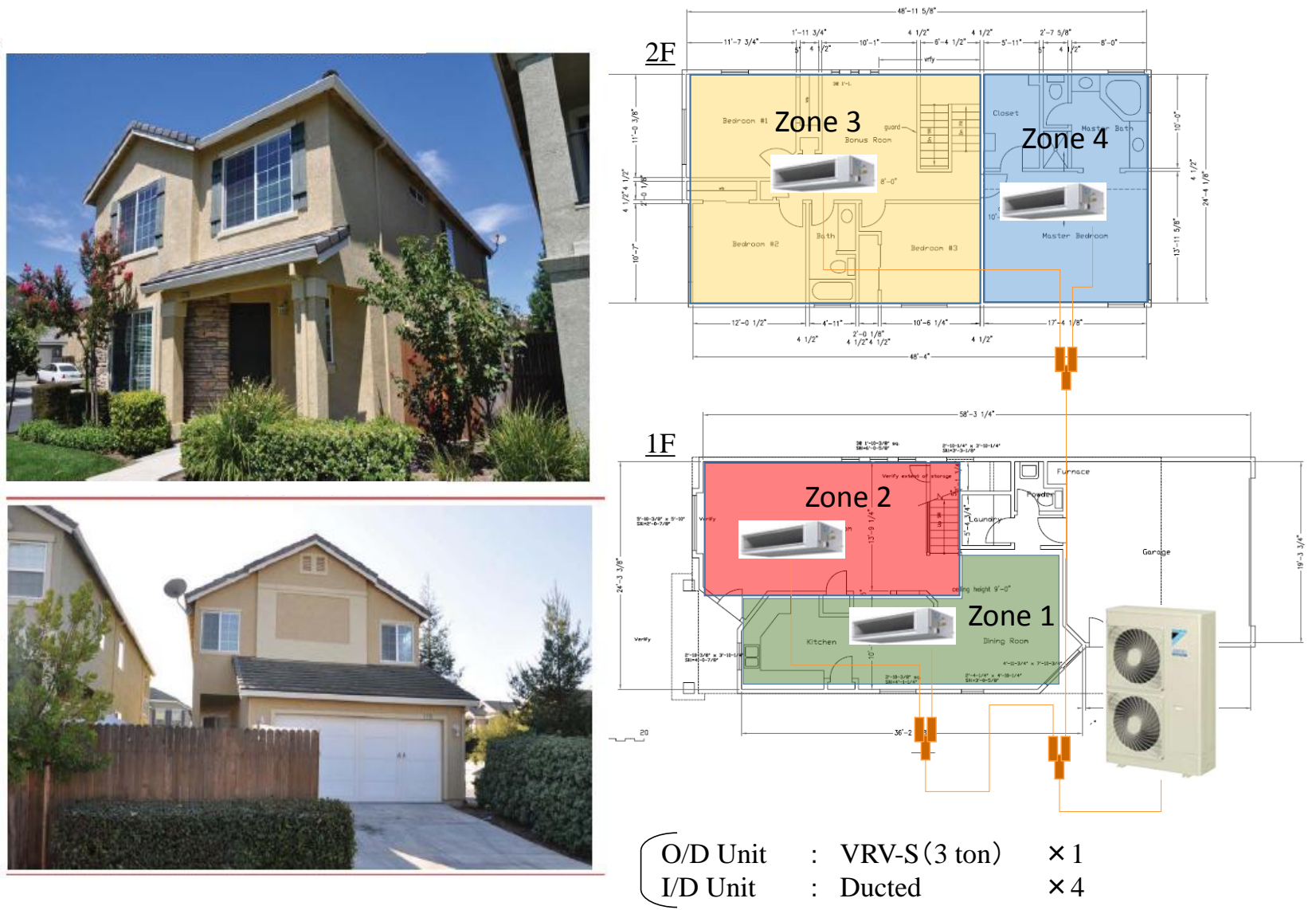

Figure 3: The Caleb House and its VRF system schematic 

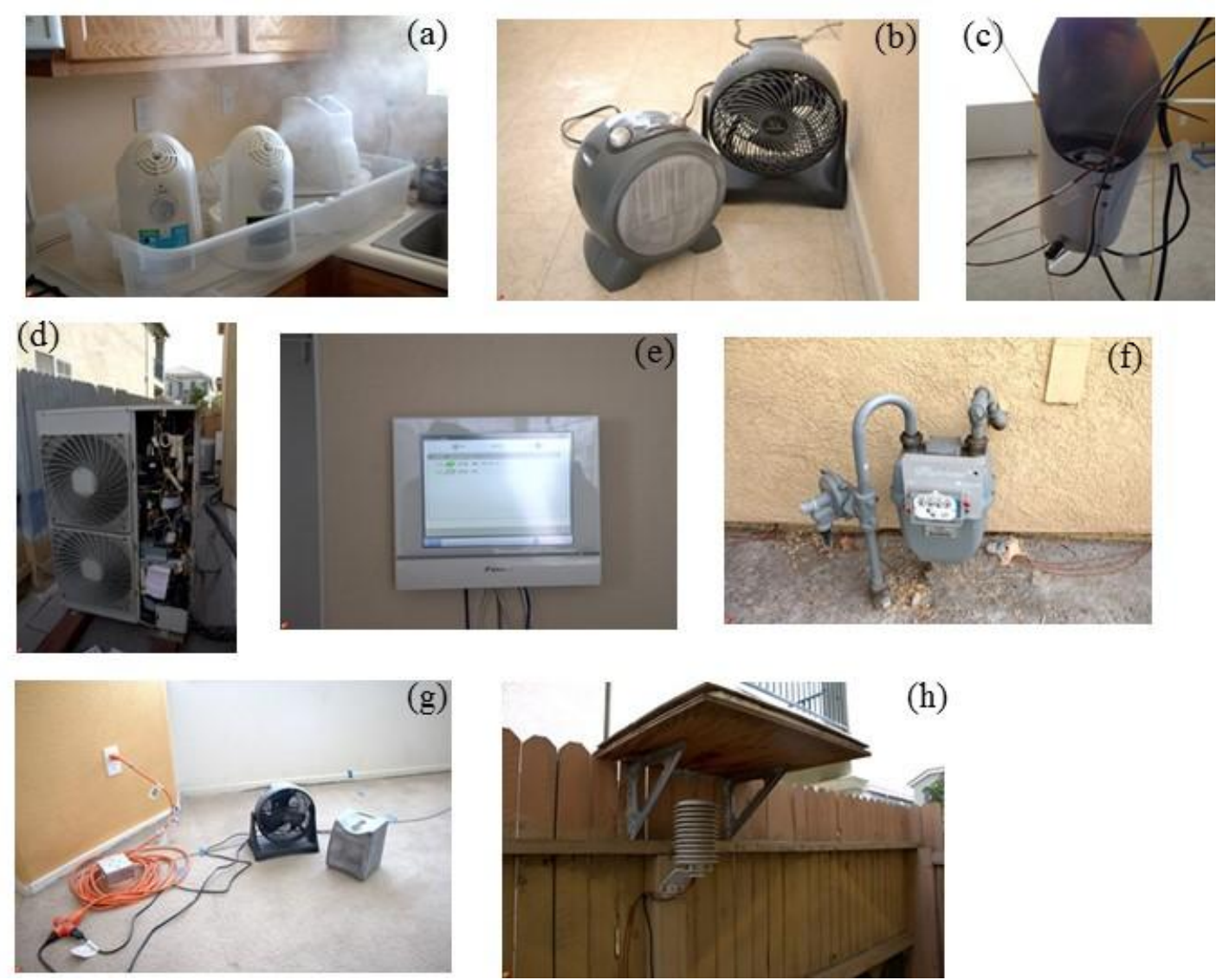

Figure 4(a-h): Building systems and sensors including: (a) humidifier, (b) electric heater and fan, (c) temperature and humidity sensor in a guest bedroom, (d) VRF outdoor unit, (e) Intelligent Control System, $(f)$ smart meter for the whole house, $(g)$ electricity monitoring for the electric heater and fan, and $(h)$ the weather station.

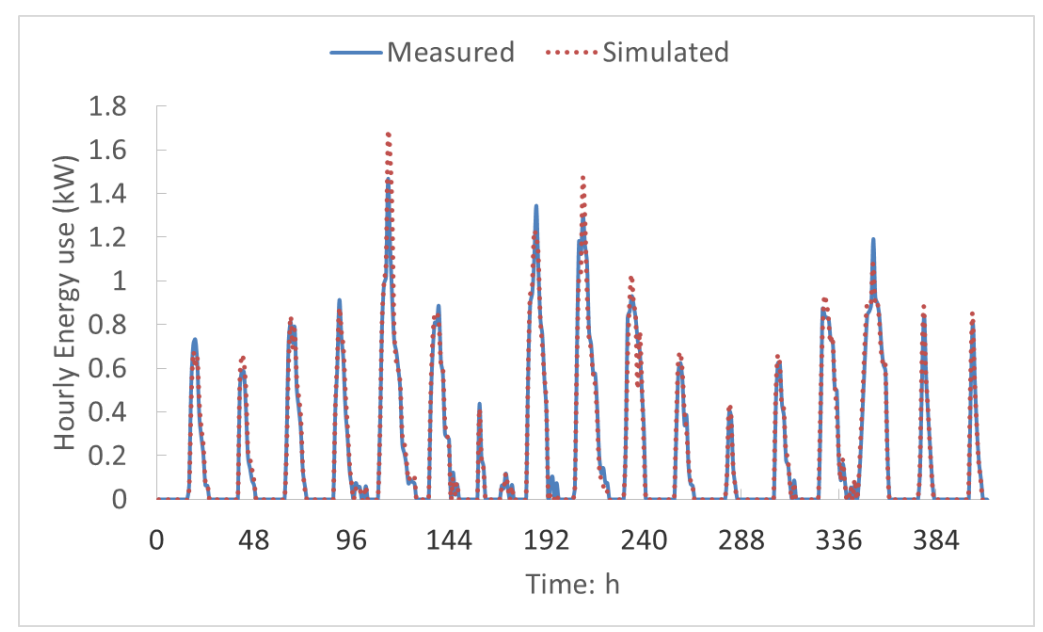


Figure 5: Hourly comparison between measured and simulated VRF energy use in cooling mode: new VRF model

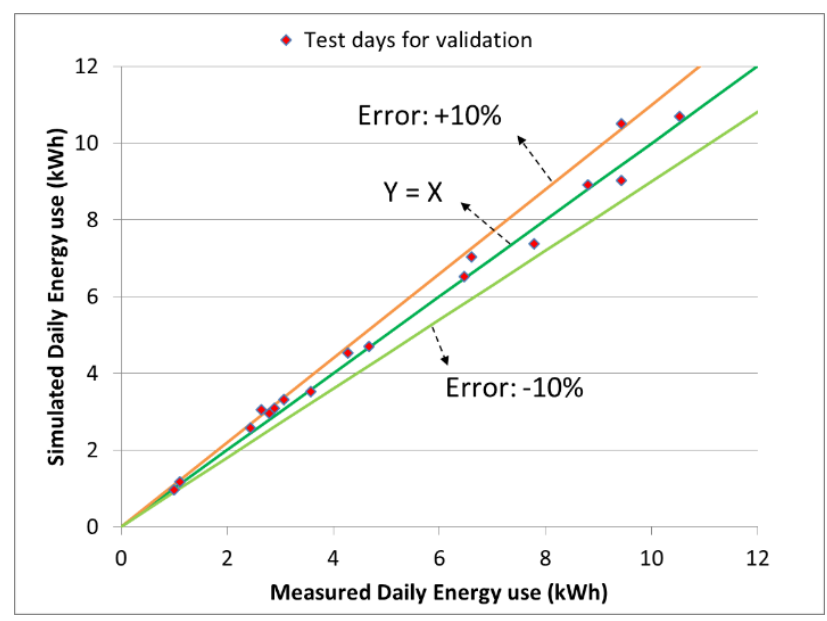

Figure 6: Errors of daily energy use in cooling mode: new VRF model

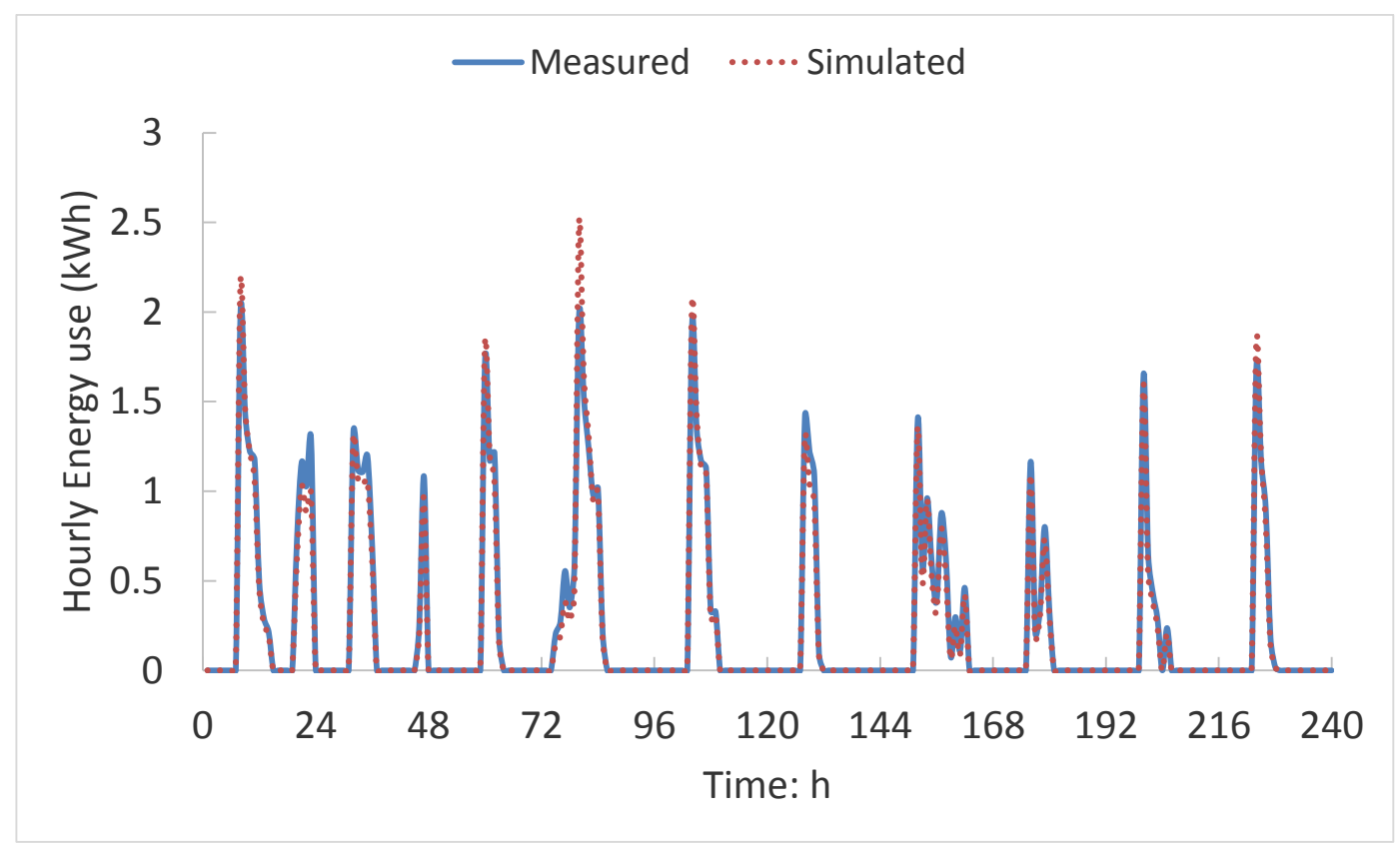

Figure 7: Hourly comparison between measured and simulated VRF energy use in heating mode: new VRF model 


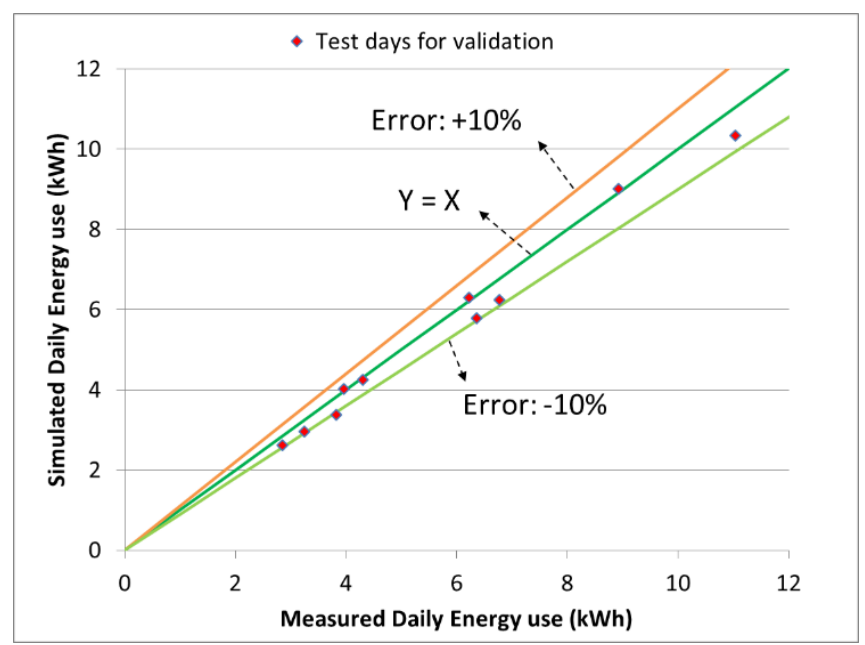

Figure 8: Errors of daily energy use in heating mode: new VRF model

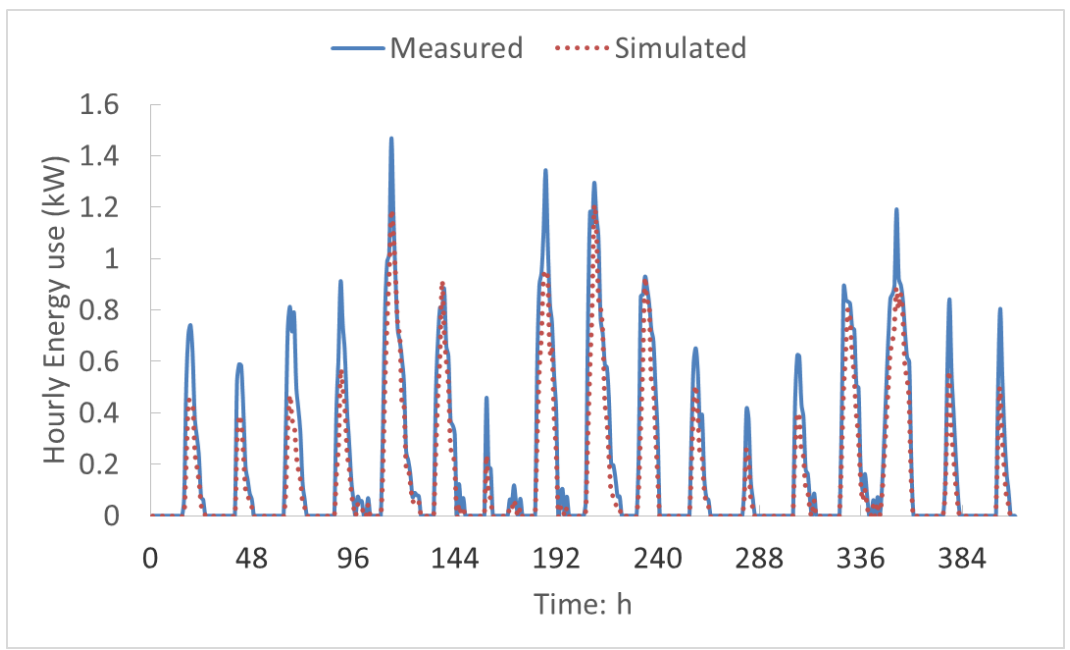

Figure 9: Hourly comparison between the measured and simulated VRF energy use in cooling mode: existing VRF model in EnergyPlus Version 7.2 


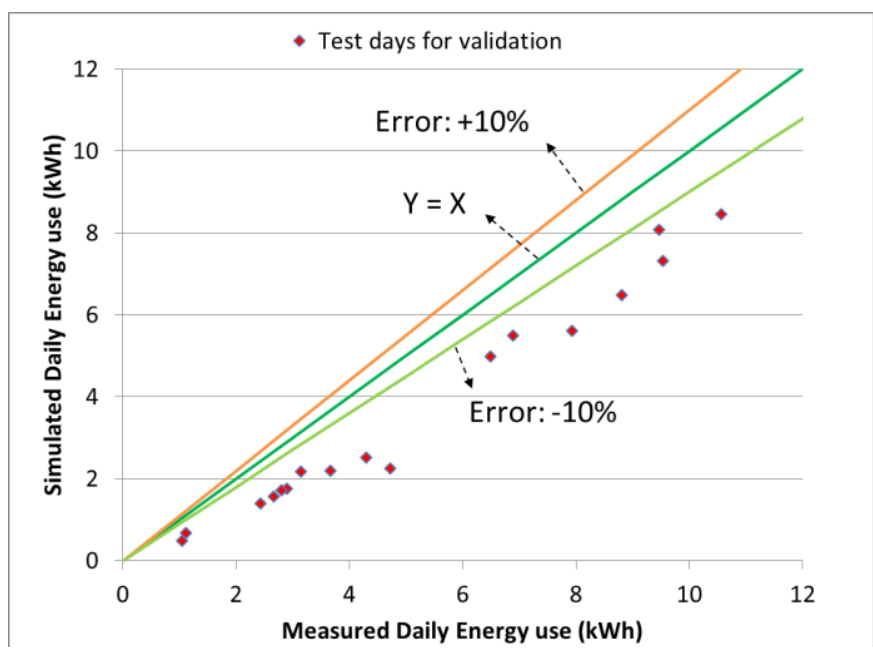

Figure 10: Errors of daily energy use in cooling mode: existing VRF model in EnergyPlus Version 7.2

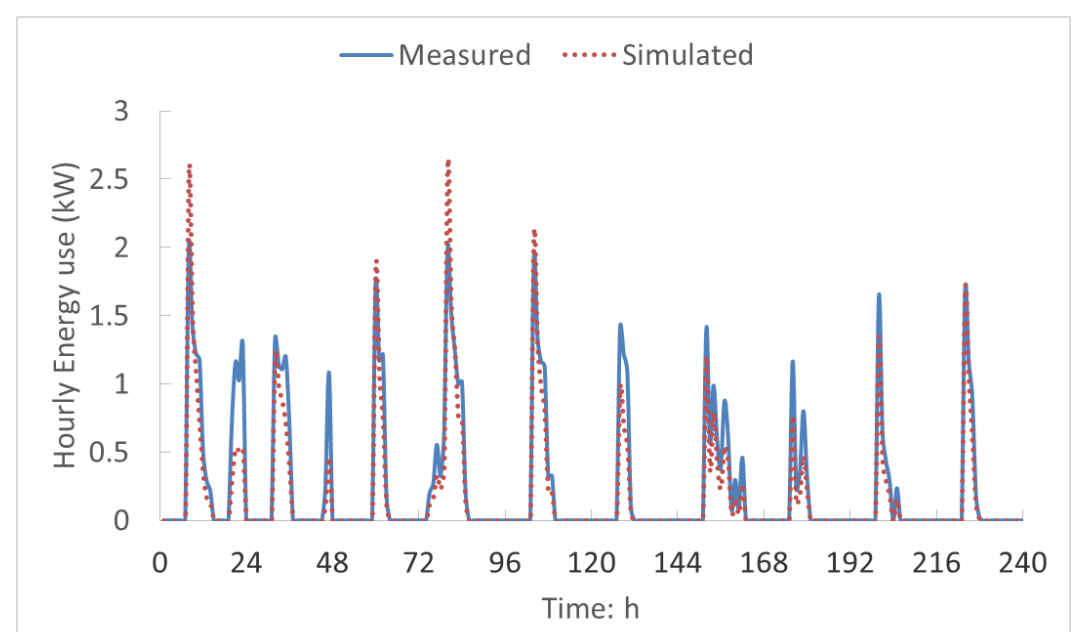

Figure 11: Hourly comparison between the measured and simulated VRF energy use in heating mode: existing VRF model in EnergyPlus Version 7.2 


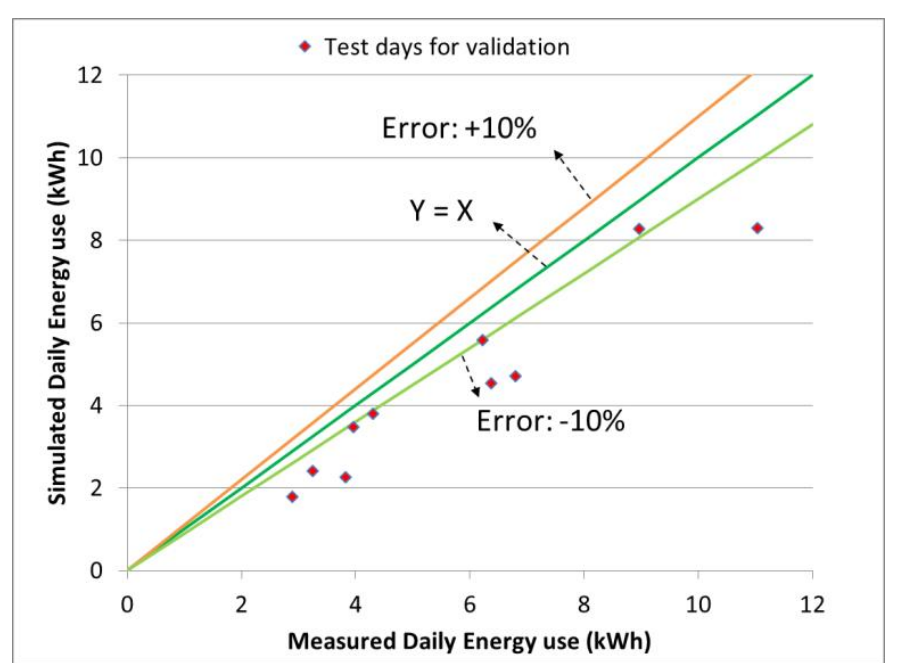

Figure 12: Errors of daily energy use in heating mode: existing VRF model in EnergyPlus Version 7.2

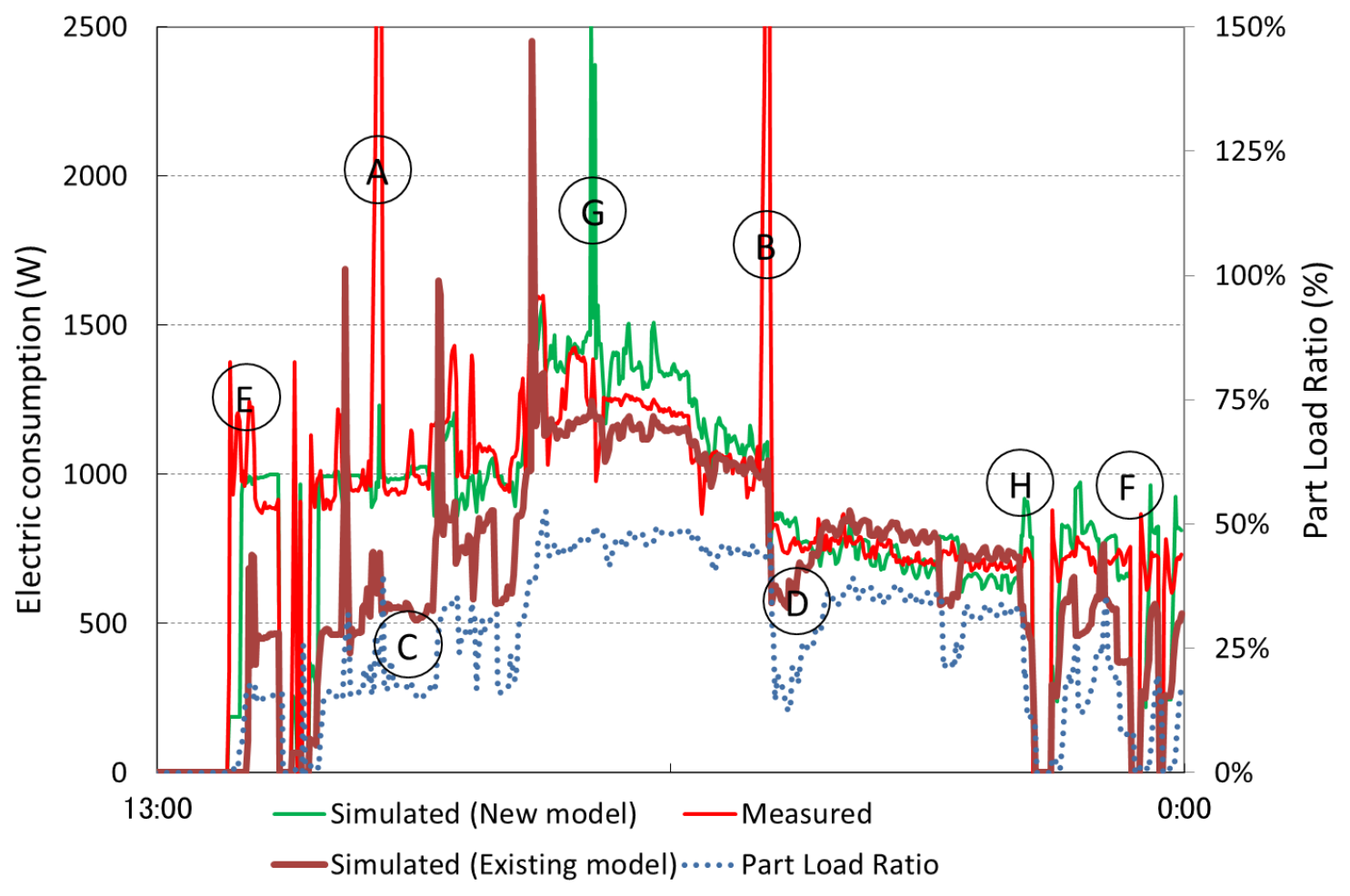

Figure 13: Comparison of simulated energy use of both the new and existing VRF models and the measured data by minute 


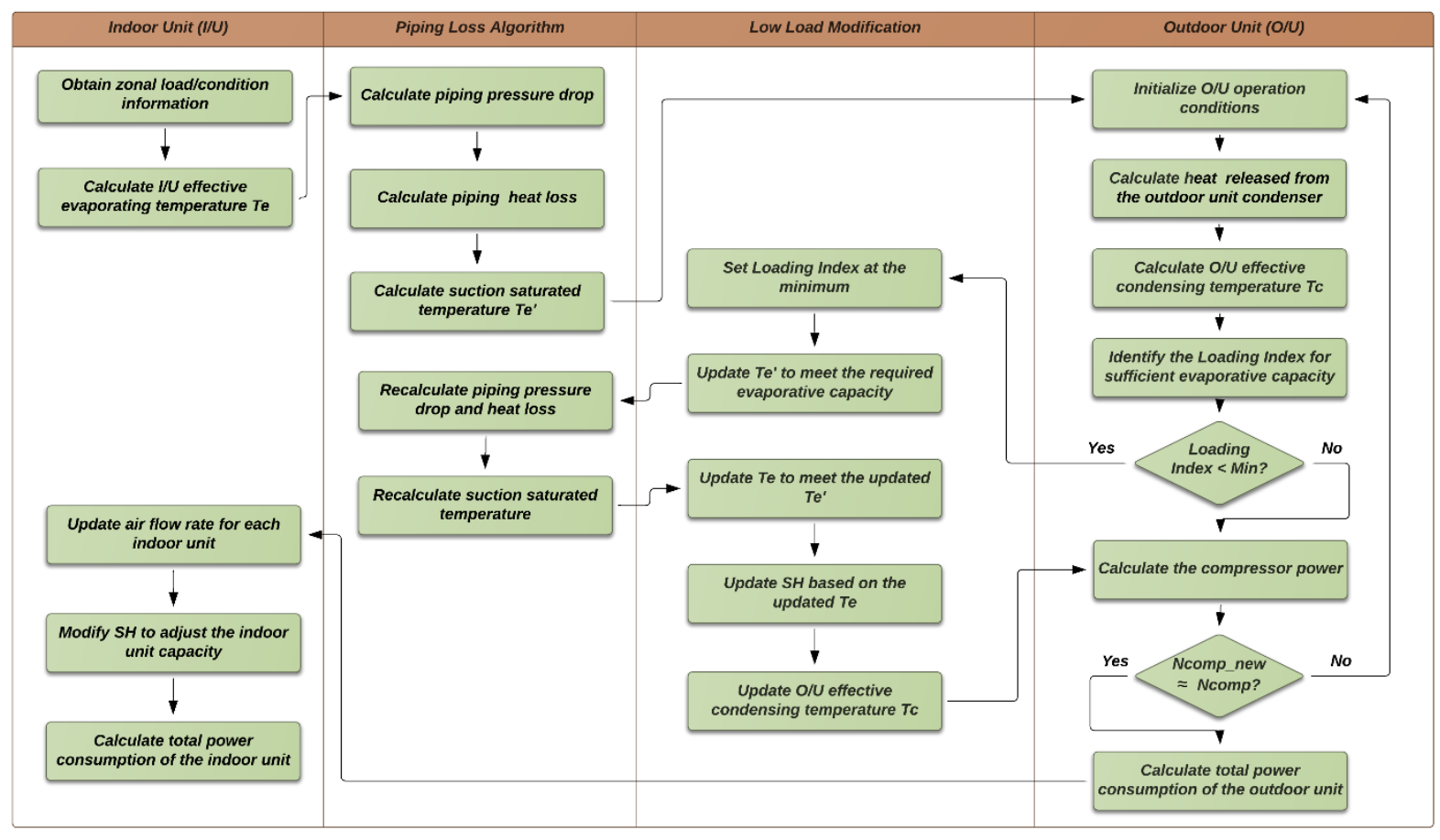

Figure 14: Schematic chart of the new VRF-HP algorithm at cooling mode 